\author{
FRANCEMED \\ (Rania ABdellatif, Yassir BeNHIMA, Daniel KÖNIG, Elisabeth RuCHAUd)
}

\title{
Introduction à l'étude des transferts culturels en Méditerranée médiévale Aspects historiographiques et méthodologiques
}

\begin{abstract}
Creuset millénaire de civilisations diverses, la Méditerranée n'a cessé d'être le réceptacle d'une dense et féconde imbrication des peuples et des cultures. Son passé médiéval, longtemps stigmatisé au nom des clivages politiques et religieux, ne déroge pas à cette règle et s'avère de plus en plus marqué par la prégnance des contacts et des échanges culturels. Replacer ces derniers au centre de la réflexion historique met en valeur les circulations permanentes et la perméabilité des différentes sociétés, en l'occurrence ici celles de l'espace méditerranéen médiéval. Cela interroge la validité des schémas culturalistes qui opposent des blocs monolithiques, au moment où les questions des relations interculturelles se posent avec acuité dans nos sociétés contemporaines.
\end{abstract}

La notion de »transferts culturels« nous est ainsi apparue comme un moyen efficace d'examiner les connexions culturelles médiévales dans leur complexité. Mais pour en faire une approche bien outillée, il a fallu nous approprier, adapter et accommoder un terme forgé pour saisir des contextes historiques différents de la Méditerranée médiévale. Ainsi, le présent travail se veut une introduction à l'histoire et à la portée d'une notion que nous nous sommes efforcés de redéfinir afin de répondre au mieux aux défis qu'impose l'analyse historique de cet espace méditerranéen.

\section{HISTOIRE D'UNE NOTION: AUX ORIGINES DU TRANSFERT CULTUREL}

Faire l'historique d'un concept représente généralement une tâche ardue qui non seulement demande l'identification des conditions de la genèse d'un terme donné, mais aussi exige la restitution de l'évolution épistémologique d'un vaste champ de recherche. Le transfert culturel, en tant que notion élaborée pour penser les liens entre les cultures dans leur dynamique permanente, n'échappe pas à cette règle. La contextualisation de cette notion reviendrait à en retracer l'évolution récente et à en définir les sources théoriques en la replaçant parmi les autres concepts employés dans l'approche des relations interculturelles.

Si les phénomènes de contact culturel ont longtemps intéressé les historiens, ces derniers sont, de par la nature même de la pratique historienne, généralement peu enclins à des tentatives de théorisation. Mais l'œuvre de certains grands historiens a laissé une place à l'étude des mécanismes de contact entre différentes cultures, reflé- 
tant de la sorte l'intérêt de l'histoire, en tant que discipline des sciences sociales, pour cette question.

Dans son ouvrage de synthèse »A Study of History «, Arnold Toynbee expose dans deux chapitres successifs la multiplicité des »rencontres « (encounters) entre les civilisations, respectivement dans l'espace et dans le temps. Le premier genre de rencontres entre civilisations contemporaines est principalement conçu dans le cadre de tentatives d'expansion ou de formes de diffusions pacifiques ${ }^{1}$. Le second a été envisagé sous trois angles: la »renaissance«, définie comme l'effort d'une civilisation en construction pour s'approprier le patrimoine d'une autre morte depuis longtemps; la »relation de filiation et de parenté « entre une civilisation morte et son successeur; et finalement l'»archaïsme«, tentative de retour à une phase antérieure de l'histoire d'une civilisation ${ }^{2}$.

Fernand Braudel a également traité du rôle du contact entre les cultures et les civilisations. À l'encontre d'une historiographie traditionnelle, représentée notamment par Toynbee - mais aussi par plusieurs philosophes de l'histoire (Comte, Marx, Spengler) -, Braudel rejette d'emblée toute lecture organique de l'histoire des civilisations et plaide pour l'étude des éléments imbriqués qui fondent et définissent les cultures3. L'apport de Braudel provient également de l'attention qu'il prêta à la question de l'échelle de l'analyse historique, que ce soit dans sa dimension spatiale ou temporelle. Les différentes temporalités qu'il mit en valeur participent effectivement d'une meilleure appréhension des différents niveaux et rythmes de l'évolution des cultures ${ }^{4}$. Si sa "Grammaire des civilisations « demeure, dans sa présentation, plutôt prisonnière d'une vision contingente de l'histoire universelle, l'ensemble de son œuvre a souligné l'ambivalence des grands ensembles culturels. Selon lui, les civilisations sont »fraternelles et libérales, mais en même temps fermées, exclusives, revêches [...] pacifiques et non moins guerrières; d'une étonnante fixité, et en même temps, mobiles, vagabondes « ${ }^{5}$. C'est justement à travers cette vision complexe qu'il a énoncé les trois critères nécessaires pour »définir une civilisation«: les aires culturelles, décrites comme l'espace et tout ce qu'il englobe de biens et traits culturels dont l'ubiquité et la fréquence fixent »les premiers signes d'une cohérence culturelle « ${ }^{6}$; les emprunts, compris comme toutes les circulations de biens culturels entre les civilisations; et enfin les refus d'emprunt, latents ou conscients, prédéterminant un ensemble de choix culturels?

1 Arnold J. ToYnBeE, A Study of History. Vol. 2, Abridgement of Volumes VII-X by D.C. SOMERVELL, New York, Londres 1987, ( $1^{\text {re }}$ éd. 1957), p. 147-240.

2 Ibid., p. 241-260.

3 Fernand BRAUDEL, Écrits sur l'histoire, Paris 1994 (1 $1^{\text {re }}$ éd. 1969), p. 289-291.

4 Sur la division braudélienne des rythmes du temps historique, ibid., p. 41-83. Voir aussi les études de Jean LEDUC, Les historiens et le temps. Conceptions, problématiques, écritures, Paris 1999, p. 21-33; François Dosse, L'histoire en miettes. Des »Annales« à la »nouvelle histoire«, Paris ${ }^{2} 1997$, p. $105-118$.

5 Phrase citée dans l'introduction de Maurice AYMARD à la réédition de l'ouvrage de Fernand BRAUDEL, Grammaire des civilisations, Paris 1987 ( $1^{\text {re }}$ éd. 1963), p. 17.

6 BRAUDEL, Écrits sur l'histoire (voir n. 3), p. 292.

7 Ibid., p. 294-296. 
L'apport de Braudel pour penser l'histoire des civilisations est multiple, mais son importance réside surtout dans son dialogue permanent avec les autres disciplines des sciences sociales. La définition même de la civilisation, évoquée plus haut, est empruntée aux travaux de Marcel Mauss. La position centrale de l'anthropologie, comme science de l'Humain dans l'articulation de sa globalité et de ses particularismes, se justifie clairement dans cette quête du sens et des mécanismes du contact culturel. Les anthropologues ont été les premiers sensibilisés aux phénomènes divers du contact culturel. La pluralité des approches et des cadres notionnels qu'ils mirent en œuvre témoigne de la richesse des méthodes et des contextes d'étude mais aussi de l'historicité des notions utilisées, notions marquées par l'empreinte de leur espace et lieu de production.

Ce détour par l'anthropologie pour cerner les conditions de création et d'évolution des notions parallèles aux transferts culturels est indispensable pour éviter les écueils d'un eurocentrisme encore trop vivace dans la tradition historique occidentale. L'anthropologie, en tant que discipline vouée, à l'origine, à l'étude des mondes extraeuropéens, s'est repositionnée depuis les temps de la décolonisation dans une posture méthodologique qui valorise la diversité des cultures et qui s'insurge contre les ravages de l'ethnocentrisme occidental. Cette vocation de l'anthropologie, heureusement reprise par la pratique historienne contemporaine, est exprimée d'une manière claire par Claude Lévi-Strauss dans un petit ouvrage-manifeste, composé sur la demande de l'Unesco, où il met en valeur la centralité de la »collaboration des cultures« dans l'histoire universelle'.

Au-delà donc de la contribution des historiens, le domaine des relations intra-, inter- et transculturelles constitue depuis longtemps un champ foisonnant de la recherche en sciences sociales. Plusieurs notions ont été élaborées, dans des contextes historiques et intellectuels variés, reflétant des visions contrastées et des concepts en évolution. Aussi, parler des transferts culturels comme notion expérimentale et de ses applications potentielles pour l'étude de la Méditerranée médiévale, exige un tour d'horizon des notions utilisées auparavant pour décrire des réalités proches ou similaires.

\section{LA NOTION D'»ACCULTURATION«}

La notion d'»acculturation« est sans doute parmi les plus anciennes utilisées. Elle désigne »les processus complexes de contact culturel au travers desquels des sociétés ou des groupes sociaux assimilent ou se voient imposer des traits ou des ensembles de traits provenant d'autres sociétés « ${ }^{9}$.

Elle trouve son origine dans l'œuvre de Franz Boas qui, en réaction à la rigidité et l'unilinéarité des schémas d'explication évolutionnistes, mit l'accent sur »la pluralité et

8 Claude LÉVI-Strauss, Race et histoire, Paris ${ }^{3} 1987$ ( $1^{\text {re }}$ éd. 1952).

9 Jean-François BARÉ, Acculturation, dans: Pierre BONTE, Michel IZARD (dir.), Dictionnaire de l'ethnologie et de l'anthropologie, Paris 2000, p. 1. 
l'imbrication horizontale des langues et des cultures « ${ }^{10}$. Elle a ensuite été élaborée dans les travaux de l'école de Chicago comme moyen d'étudier les interactions et les influences réciproques entre cultures ${ }^{11}$. Pourtant, c'est le champ des études amérindiennes à l'époque coloniale, un contexte d'échange inégal donc, qui a servi de terrain principal à l'étude des phénomènes d'acculturation. Nathan Wachtel, en se limitant aux sociétés amérindiennes, distingue deux situations différentes: l'acculturation imposée, lorsque la domination coloniale aspire au contrôle complet de la société dominée en bouleversant ses structures sociales, économiques, politiques et culturelles; et l'acculturation spontanée qui, agissant d'abord sur les marges des zones dominées par les Européens, peut aussi concerner des aspects non imposés par le système dominateur. Ces deux formes d'acculturation mettent en œuvre deux processus opposés, mais néanmoins complémentaires: l'intégration par le système indigène d'éléments allogènes; et l'assimilation, consistant en l'adoption de traits culturels de la société dominante en substitution d'éléments indigènes ${ }^{12}$.

Cette définition de l'acculturation, sans doute conditionnée par le contexte colonial dont elle rend compte, souffre de quelques limites. Elle induit implicitement que le processus de changement culturel intervient entre une culture >source< et une culture >cible`, sans pour autant insister sur les modalités du changement. Par ailleurs, la réduction de la culture à une juxtaposition de straits culturels` identifiables, dans la culture >source puis dans la culture >cible<, n'offre qu'une lecture partielle des cultures en présence qui méritent pourtant d'être appréhendées en tant que systèmes complexes où l'influence externe est une composante essentielle ${ }^{13}$. Pour dépasser ces limites, certains concepts parallèles ont vu le jour (»transculturation « ${ }^{14}$ et $»$ interculturation $\left.\ll 15\right)$, sans pour autant s'imposer comme des alternatives incontournables.

\section{LA NOTION DE »MÉTISSAGE«}

Comme pour l'acculturation, c'est la recherche sur l'Amérique à l'époque coloniale qui a mis en exergue la notion de »métissage« comme concept phare des études sur les contacts et les changements culturels. Le mot »métissage« conserve dans son étymolo-

10 Michel Espagne, La question des imbrications culturelles chez Franz Boas, dans: Revue germanique internationale 17 (2002), p. 147-160.

11 Laurier TURGEON, Les mots pour dire les métissages: jeux et enjeux d'un lexique, dans: Revue germanique internationale 21 (2004), p. 53-69 (p. 54).

12 Nathan Wachtel, L'acculturation, dans: Jacques Le Goff, Pierre NorA (dir.), Faire de l'histoire, vol. 1: Nouveaux problèmes, Paris 1974, p. 180-184.

13 BARÉ, Acculturation (voir n. 9), p. 2.

14 Selon Turgeon, Les mots pour dire les métissages (voir n. 11), p. 54, stransculturation fut utilisé pour rendre compte d'éléments amérindiens adoptés par la culture européenne, décrivant par la sorte un processus opposé à l'acculturation.

15 Ibid., p. 57, l'»interculturation« fut institué par les anthropologues Ruth Benedict et Margaret Mead pour »modéliser les processus interactifs et les échanges bilatéraux, voire multilatéraux, entre groupes différents«. Ses applications sont restées cantonnées dans le domaine des études socio- et psycho-linguistiques des communautés immigrées. 
gie même les traces de son histoire. Utilisé d'abord en portugais puis en espagnol, le mestizo (sang-mêlé, terme dérivant du latin mixtus) désignait à l'origine la catégorie des enfants issus d'unions entre Européens et Indiennes. Il garda longtemps cette connotation imprégné de laquelle le mot »métis« fit son apparition en français au $\mathrm{XVII}^{\mathrm{e}}$ siècle. Il est alors associé à toute une terminologie de rejetons des unions mixtes dans les Amériques, là où l'élément européen s'est mélangé, biologiquement et culturellement parlant, au substrat indien et aux apports d'esclaves déportés depuis l'Afrique noire ${ }^{16}$. Empreinte des fondements encombrants de la raciologie de l'époque moderne, la nomenclature du métissage est marquée par la comparaison avec le règne animal et elle est destinée à stigmatiser un phénomène déconsidéré socialement. À titre d'exemple, le mot »mulâtre«, dérivé de »mulet«, est employé pour qualifier les enfants issus de l'union entre Noirs et Blancs; la métaphore se rapportant à un animal engendré par le croisement d'espèces différentes condamne ainsi une anomalie humaine ${ }^{17}$. Ce champ sémantique du croisement biologique a donné naissance au XIX ${ }^{\mathrm{e}}$ siècle au terme "métissage«, tout d'abord pour qualifier l'hybridité chez les ovins, avant de s'étendre au domaine des relations humaines.

Exposer le caractère si négatif des significations associées jadis au mot »métissage« suffit à montrer l'ampleur du chemin parcouru par une notion aujourd'hui pleinement valorisée. Le métissage culturel est devenu, après la fin de l'ère coloniale, un synonyme de phénomènes culturels multidimensionnels et omniprésents, et il est dorénavant considéré comme indissociable de la construction et de l'évolution des cultures. Parallèlement à l'extension de la notion depuis la biologie vers les différents domaines de la culture, le métissage a évolué pour caractériser une pensée >métisse`, défiant le cloisonnement habituel des cultures et de la recherche de la matrice ou des filiations culturelles, pour envisager la multiplicité et la rencontre ${ }^{18}$. Ainsi, penser en terme de métissage revient à abandonner la fiction du >purく et de l'>originel〈, qui a tellement conditionné la construction des catégories culturelles, pour comprendre ces dernières et en affiner l'analyse ${ }^{19}$.

Si le métissage est devenu en anthropologie un paradigme important, les historiens ne semblent pas en faire un usage fréquent. La contribution de Serge Gruzinski, qui a délimité à travers l'exemple de la Nouvelle-Espagne les termes de l'analyse du métissage comme une réalité accompagnant la situation coloniale, est sans doute l'une des plus remarquées ${ }^{20}$. De son côté, Jocelyne Dakhlia s'interroge sur les blocages épistémologiques et les conditions historiques qui ont empêché de penser la Méditerranée médiévale et moderne en terme de métissage. Tout en notant l'impact de la fracture

16 Voir p.ex. Nelly SCHMIDT, Histoire du métissage, Paris 2003, p. 63-67.

17 TuRgEON, Les mots pour dire les métissages (voir n. 11), p. 58-59.

18 François LaPlantine, Alexis Nouss, Le métissage, Paris 1997 (Dominos, 145), p. 83, écrivent à ce propos: »Penser le métissage comme étant hétérogène et hétérodoxe par rapport à ce qui le précéderait (par exemple l'informe par rapport à la forme), c'est encore se référer au dualisme de l'originel et du dérivé. Or, la pensée métisse brouille [...] ces catégories binaires, elle déclassifie, décatégorise«.

19 Sur les déterminants d'une épistémologie du métissage, voir ibid., p. 88-91.

20 Serge GruZINSKI, La pensée métisse, Paris 1999. 
coloniale dans cette situation, elle relève la part de l'image de l'altérité musulmane dans la construction d'un savoir historique sur la Méditerranée. Elle souligne enfin le caractère >métis` de nombre de phénomènes de brassage en Méditerranée et, à travers l'exemple emblématique de la lingua franca, montre la possibilité de penser les cultures comme des ensembles ouverts, pouvant le cas échéant se replier sur une identité nucléaire ${ }^{21}$.

Également issu du champ sémantique de la biologie, le terme »hybridity« est utilisé dans le monde anglo-saxon comme équivalent au métissage. Un premier effort d'adaptation de la notion aux phénomènes sociaux a été entrepris au début du $\mathrm{XX}^{\mathrm{e}}$ siècle ${ }^{22}$. Il faut cependant attendre les années 2000 pour voir son développement dans l'étude des usages linguistiques dans les situations de rencontre interculturelle23, puis dans les travaux sur la littérature ${ }^{24}$. Le courant des subaltern studies, qui revendique l'hybridité »comme moyen d'un renversement stratégique du processus de domination ${ }^{25}$, est parmi les plus représentatifs de ces travaux, principalement axés sur la littérature marquée par une lecture postcoloniale ${ }^{26}$. Ce n'est que très progressivement que ce terme est envisagé comme concept postcolonial adaptable aux autres disciplines des sciences sociales. Il a été adopté d'abord par les études sociologiques portant sur les phénomènes migratoires dans un contexte de globalisation ${ }^{27}$, avant que cela ne concerne les travaux historiques sur l'Antiquité tardive, le Moyen Âge, etc. ${ }^{28}$ Peter

21 Jocelyne DAKHLIA, Lingua franca. Histoire d'une langue métisse en Méditerranée, Paris 2008, en particulier p. 22-29. Voir également son article dans le présent volume.

22 Cette évolution s'exprime, par exemple, dans les titres de certains ouvrages du XIX ${ }^{\mathrm{e}}$ et du début du XX $X^{\mathrm{e}}$ siècle: Paul BrocA, Recherches sur l'hybridité animale en général et sur l'hybridité humaine en particulier: considérées dans leurs rapports avec la question de la pluralité des espèces humaines, Paris 1860; Raoul LA GRASSERIE, De l'hybridité mentale et sociale, Paris 1911.

23 Ingrid PILler, Bilingual Couples Talk. The Discursive Construction of Hybridity, Amsterdam 2002 (Studies in Bilingualism, 25); Volker HINNENKAMP, Katharina MENG (dir.), Sprachgrenzen überspringen. Sprachliche Hybridität und polykulturelles Selbstverständnis, Tübingen 2005 (Studien zur deutschen Sprache, 32).

24 Joyce Goggin, Sonja NeEF (dir.), Text, Subjectivity, Hybridity, Amsterdam 2001.

25 TURGEON, Les mots pour dire les métissages (voir n. 11), p. 63.

26 Monika FLuderniK (dir.), Hybridity and Postcolonialism. Twentieth-Century Indian Literature, Tübingen 1998 (ZAA Studies, 1); Robert Young, Colonial Desire. Hybridity in Theory, Culture, and Race, Londres 2006; Joel KUORTTI (dir.), Reconstructing Hybridity: Post-Colonial Studies in Transition, Amsterdam 2007 (Textxet, 51).

27 Virinder S. Kalra, Raminder Kaur, John HutnYK, Diaspora \& Hybridity, Londres 2005; Marwan KRAIDY, Hybridity or the Cultural Logic of Globalization, Philadelphie 2005; Kevin ARCHNER (dir.), Cultures of Globalization. Coherence, Hybridity, Contestation, Londres 2008 (Rethinking globalizations, 12); Ryoo WoONGJAE, Globalization, or the Logic of Cultural Hybridization, dans: Asian Journal of Communication 19 (2009), p. 137-151; Claus-Dieter KROHN (dir.), Exil, Entwurzelung, Hybridität, Munich 2009 (Exilforschung, 27).

${ }^{28}$ Daniel Boyarin, Hybridity and Heresy. Apartheid Comparative Religion in Late Antiquity, dans: Ania Loomba (dir.), Postcolonial Studies and Beyond, Durham 2005, p. 339-358; Jeffrey Jerome CoHEN, Hybridity, Identity, and Monstrosity in Medieval Britain, New York 2006. 
Burke s'est récemment engagé dans la réflexion sur ce terme et son adaptation aux exigences de l'histoire culturelle 29 .

\section{LA NOTION DE »TRADUCTION«}

La notion de »traduction«, empruntée au champ linguistique, est elle aussi utilisée pour penser les relations entre les cultures. La traduction entre cultures peut ainsi être envisagée comme une réalité inhérente à toute situation de contact, et non comme un phénomène ponctuel et épisodique. Elle assure »le dépassement promis et progressif de leur cloisonnement ou de leur repli sur elles-mêmes «30. Dans ce sens, la traduction peut être considérée comme un équivalent d'emprunts, d'importations ou d'exportations d'éléments culturels. Elle permet de décrire et penser le passage de biens culturels d'une aire à une autre et de définir le métissage. Dans le même temps, elle "préserve le dogme de cultures homogènes originelles« qui ne sont traduites ou métissées qu'au cours d'une seconde phase ${ }^{31}$.

La lecture des relations culturelles peut être appréhendée par le biais des différents modes de traduction. Ceux-ci peuvent être classées en trois types: la traduction intralinguale ou interprétation de signes linguistiques au moyen d'autres signes dans la même langue; la traduction interlinguale ou interprétation de signes linguistiques au moyen d'une autre langue; et finalement la traduction intersémiotique (transmutation), traduction de signes linguistiques au moyen de systèmes non linguistiques (exemple de l'adaptation cinématographique d'un roman) ${ }^{32}$. Malgré la dominance du vocabulaire linguistique, le terme »traduction«, ou en anglais »translation«, a été adapté à tous les champs possibles comme nous le montrent les travaux récents de Peter Burke et Finbarr B. Flood 33 .

29 Peter Burke, Cultural Hybridity, Cambridge 2009.

30 Marc CRÉPON, La traduction entre les cultures, dans: Revue germanique internationale 21 (2004), p. 71-82. De la même manière, une straduction` dans le sens théorique du terme peut être interne à une culture, ou envisagée dans le cadre d'un passage entre deux cultures différentes. La transmutation d'un bien culturel, à la fois dans son propre cadre de production ou à la suite de son transfert vers une autre culture, peut s'apparenter à une traduction intersémiotique.

31 Ibid., p. 74.

32 Ibid., p. 75.

33 Peter Burke, Translating Knowledge, Translating Cultures, dans: Michael NoRTH (dir.), Kultureller Austausch. Bilanz und Perspektiven der Frühneuzeitforschung, Cologne, Weimar, Vienne 2009, p. 70-76. Voir aussi Peter BURKE, Cultural Translation in Early Modern Europe, Cambridge 2008; Finbarr B. FLOOD, Objects of Translation: Material Culture and Medieval >Hindu-Muslim< Encounter, Princeton 2009. 


\section{LA NOTION DE »TRANSFERT CULTUREL»}

La notion de transfert culturel, très marquée par les travaux théoriques de Michel Espagne $^{34}$, reflète aussi cette situation. Elle a d'abord été conceptuellement élaborée pour réfléchir sur les relations intellectuelles franco-allemandes aux époques modernes et contemporaines. En critiquant certains aspects de la méthodologie comparatiste ${ }^{35}$, Espagne relève qu'elle permet de dépasser les clivages nationaux (et culturels) pour valoriser les contaminations qui mettent en relation deux systèmes autonomes, et ainsi de mettre l'accent sur les processus de réception et de transformation dans la société d'accueil ${ }^{36}$. Selon lui, le transfert culturel »signale le désir de mettre en évidence des formes de métissage souvent négligées au profit de la recherche d'identités $«{ }^{37}$. Mais même si les transferts culturels »peuvent concerner les relations entre deux tribus amérindiennes, [ils] sont plus particulièrement liés à l'autoperception des groupes comme nations « ${ }^{38}$. Dans sa démarche, l'analyse en termes de transferts culturels est un outil heuristique efficace pour cerner les manifestations des imbrications culturelles. Sans proposer d'explication globale, elle permet de réévaluer et de mettre en relief la part de l'étranger dans la construction des identités nationales. Elle opère un changement de polarité et place le rapport à l'autre au centre de la réflexion sur soi ${ }^{39}$. Ainsi, le travail historique sur les identités nationales ne peut faire abstraction d'un questionnement systématique sur les processus complexes d'emprunt et de réception. Partant de ce constat, la démarche initiée par les travaux de Espagne favorise la mise en valeur des imbrications culturelles à un moment marqué à la fois par la prégnance de la mondialisation actuelle ${ }^{40}$ et par la force des clivages identitaires. Mettre en valeur l'historicité des combinaisons culturelles participe aussi d'une réflexion sur le temps présent, réflexion déjà entamée d'une manière approfondie par d'autres disciplines des sciences sociales ${ }^{41}$.

La notion de transfert culturel ne semble pas avoir fait écho parmi les historiens francophones où on ne trouve que quelques écrits - à part les publications de Espagne -

34 Notamment Michel EsPAGNE, Les transferts culturels franco-allemands, Paris 1999; Katia DMITRIEVA, Michel EsPagne (dir.), Transferts culturels triangulaires France - Allemagne Russie, Paris 1996 (Philologiques, 4).

35 Voir Johannes PAULMANN, Internationaler Vergleich und interkultureller Transfer. Zwei Forschungsansätze zur europäischen Geschichte des 18. bis 20. Jahrhunderts, dans: Historische Zeitschrift 267 (1998), p. 668-671.

36 Michel Espagne, Du creuset espagnol à l'Espagne hors les murs. Vers une approche de la culture hispanique en ses contextes, dans: Mélanges de la Casa de Velázquez 38/2 (2008), p. 113-126. Voir aussi: http://mcv.revues.org/775 [15/11/2010] (2/2/2011).

37 ESPAGNE, Les transferts culturels franco-allemands (voir n. 34), p. 1.

38 Ibid.

39 Ibid., p. 267-269.

40 Sur l'histoire du monde >mondialisé` au début de l'époque moderne: Serge GRUZINSKI, Les quatre parties du monde. Histoire d'une mondialisation, Paris 2004.

${ }^{41}$ Sur les rapports entre l'émergence de la notion de transfert culturel et les tendances récentes de la global history au temps de la mondialisation, voir François CHAUBET, La notion de transfert culturel dans l'histoire culturelle, dans: Benoît PeLLISTRANDI, Jean-François SiRINELLi (dir.), L'histoire culturelle en France et en Espagne, Madrid 2008 (Collection de la Casa de Velázquez, 106), p. 159-177, surtout p. 159. 
qui utilisent ce concept, en se bornant en général à l'étude des époques moderne et contemporaine, et notamment des relations franco-allemandes ${ }^{42}$. En Allemagne, en revanche, les recherches de Michel Espagne ont déclenché une vague de publications se servant de ce concept adapté à toutes les époques de l'Antiquité à nos jours ${ }^{43}$. Ainsi, l'époque médiévale a aussi été analysée via ce concept: des actes de colloques allemands, franco-allemands et italo-allemands ${ }^{44}$, plusieurs travaux récents ${ }^{45}$ ainsi qu'un projet de recherche financé par l'Agence allemande pour la recherche (DFG) - le Graduiertenkolleg »Kulturtransfer im Mittelalter« à l'université d'Erlangen - ont été consacrés à l'étude des transferts culturels à l'époque médiévale. La notion de transfert culturel, qui avait été aussi développée par des chercheurs germanophones comme Michael Werner, Wolfgang Schmale, Matthias Middell et d'autres ${ }^{46}$, fut adaptée en

42 Voir Michel GrIMBERG, La réception de la comédie française du XVIII siècle dans l'aire germanophone de 1694 à 1799 , vue à travers les traductions et leurs préfaces, thèse doctorale, université Sorbonne-Paris IV 1994; Jan VON ROSEN, Le transfert culturel comme transformation de discours. Mme de Staël interprète de l'esthétique kantienne, thèse doctorale, université de Caen 2003; Amaury Du Closel, Philippe Olivier (dir.), Déracinements. Musique, exil et transfert culturel pendant et après le Troisième Reich, Paris 2008; Mathilde KANG, Le parcours transatlantique du »Journal« d'Eugénie de Guérin. Un cas de transfert culturel, 1850-1950, Oxford, Berne, Berlin 2009 (French Studies of the Eighteenth and Nineteenth Centuries, 27); Christine LOMBEZ, La traduction de la poésie allemande en français dans la première moitié du $\mathrm{XIX}^{\mathrm{e}}$ siècle: réception et interaction poétique, Tübingen 2009 (Communicatio, 40).

43 Voir Claude D. CONTER, Vom Kulturtransfer zum Kulturexport. Der Bund Rheinischer Dichter und die Gesellschaft für deutsche Literatur und Kunst. Anmerkungen zur Literaturpolitik in Luxemburg zwischen 1933 und 1945, dans: Dieter BREUER (dir.), Das Rheinland und die europäische Moderne. Kulturelle Austauschprozesse in Westeuropa 1900-1950, Essen 2008; Christoph Michels, Kulturtransfer und monarchischer >Philhellenismus«. Bithynien, Pontos und Kappadokien in hellenistischer Zeit, Göttingen 2009 (Schriften zur politischen Kommunikation, 4).

${ }^{44}$ Hubert Houben, Benedetto VeTERE (dir.), Pellegrinaggio e Kulturtransfer nel Medioevo europeo. Pilgerwesen und Kulturtransfer im europäischen Mittelalter, Lecce 2006 (Pubblicazioni del Dottorato in Storia dei Centri delle Vie e delle Culture dei Pellegrinaggi nel Medioevo Euromediterraneo, 2); Stephen DöRR, Raymund WILhELM (dir.), Transfert des savoirs au Moyen Âge. Wissenstransfer im Mittelalter. Actes de l'atelier franco-allemand, Heidelberg, 15-18 janvier 2008, Heidelberg 2008 (Studia Romanica, 144); Johannes FRIED, Gundula GREBNER (dir.), Kulturtransfer und Hofgesellschaft im Mittelalter. Wissenskultur am sizilianischen und kastilischen Hof im 13. Jahrhundert, Berlin 2008 (Wissenskultur und gesellschaftlicher Wandel, 15).

45 Friedrich PRINZ, Von den geistigen Anfängen Europas. Der Kulturtransfer zwischen christlicher Spätantike und Frühmittelalter, dans: Dieter HäGERmANN, Wolfgang HAUBRICHS, Jörg JARNUT (dir.), Akkulturation: Probleme einer germanisch-romanischen Kultursynthese in Spätantike und frühem Mittelalter, Berlin 2004 (Ergänzungsbände zum Reallexikon der germanischen Altertumskunde, 41), p. 1-17; Florian STEGER, Kay Peter JANKRIFT (dir.), Gesundheit Krankheit. Kulturtransfer medizinischen Wissens von der Spätantike bis in die frühe Neuzeit, Cologne, Weimar, Vienne 2004; Dominik WASSENHOVEN, Skandinavier unterwegs in Europa (1000-1250). Untersuchungen zu Mobilität und Kulturtransfer auf prosopographischer Grundlage, Berlin 2006 (Europa im Mittelalter, 8); Eva Schlotheuber, Hubertus SeIBerT (dir.), Böhmen und das Deutsche Reich. Ideen- und Kulturtransfer im Vergleich (13.-16. Jh.), Munich 2009 (Veröffentlichungen des Collegium Carolinum, 116).

46 Voir Wolfgang SCHMALE, Historische Komparatistik und Kulturtransfer. Europageschichtliche Perspektiven für die Landesgeschichte, Bochum 1998 (Herausforderungen, 6); ID. (dir.), Kulturtransfer. Kulturelle Praxis im 16. Jahrhundert, Innsbruck 2003 (Wiener Schriften zur Ge- 
conséquence aux besoins d'une recherche médiévistique, recourant parfois à un 〉Espagne simplifié ‘ comme grille de lecture permettant de transférer une théorie issue d'un contexte d'une Europe des nations à un contexte médiéval qui ne connaît pas encore de cultures nationales ${ }^{47}$.

En France, si la notion de transfert culturel, telle qu'elle apparaît dans la démarche de M. Espagne, commence à être expérimentée sur des terrains différents de ses premiers champs d'application franco-allemands ${ }^{48}$, elle demeure peu utilisée pour l'histoire de la Méditerranée médiévale.

Sans aborder la question des contacts et imbrications culturels sous l'angle exclusif des transferts culturels, une entreprise européenne récente mérite toutefois d'être soulignée. La série des Cultural Exchange in Early Modern Europe ${ }^{49}$ a aussi opté pour une utilisation de la notion de transfert au-delà du strict cadre des relations nationales bilatérales ou triangulaires ${ }^{50}$. Mais le terme d'échange culturel, utilisé par Burke pour désigner d'une manière générique tous les phénomènes que nous avons mentionnés ${ }^{51}$, demeure, selon Bernd Roeck, plus adéquat pour décrire un processus dynamique impliquant plusieurs protagonistes actifs, à la différence du transfert, qui sous-entend une relation entre un donneur actif et un récepteur passif 52 .

schichte der Neuzeit, 2); Matthias MIDDELL, Kulturtransfer und Historische Komparatistik. Thesen zu ihrem Verhältnis, dans: ID. (dir.), Kulturtransfer und Vergleich, Leipzig 2000 (Comparativ - Leipziger Beiträge zur Universalgeschichte und vergleichenden Gesellschaftsforschung, 10,1), p. 7-41; ID., Von der Wechselseitigkeit der Kulturen im Austausch. Das Konzept des Kulturtransfers in verschiedenen Forschungskontexten, dans: Andrea LANGER, Georg Michels (dir.), Metropolen und Kulturtransfer im 15.-16. Jh., Stuttgart 2001 (Forschungen zur Geschichte und Kultur des östlichen Mitteleuropa, 12), p. 15-51; Michael WERNER, Zum theoretischen Rahmen und historischen Ort der Kulturtransferforschung, dans: Michael NORTH (dir.), Kultureller Austausch in der Frühen Neuzeit. Bilanz und Perspektiven der Frühneuzeitforschung, Cologne, Weimar, Vienne 2009, p. 15-24.

47 Voir StEger, JANKRIFT, Gesundheit - Krankheit (voir n. 45), p. 4-10.

48 Voir à ce propos le dossier publié dans les Mélanges de la Casa de Velázquez 38/2 (2008) sur les transferts culturels en Espagne à l'époque moderne: Hélène BEAUCHAMP, Anne-Cécile Druet, Axelle Guillausseau (dir.), Transferts culturels dans le monde hispanique/Transferencias culturales en el mundo hispánico, dans: Mélanges de la Casa de Velázquez 38/2 (2008); voir aussi: http://mcv.revues.org/775 [15/11/2010] (2/2/2011); Laurier TURGEON, Denis Delage, Réal Ouellet (dir.), Transferts culturels et métissage Amérique/Europe XVI ${ }^{\mathrm{e}}-$ $\mathrm{XX}^{\mathrm{e}}$ siècle, Laval 1996.

49 Robert Muchembled (dir.), Cultural Exchange in Early Modern Europe, vol. 1: Religion and Cultural Exchange in Europe, 1400-1700; vol. 2: Cities and Cultural Exchange in Europe, 1400-1700; vol. 3: Correspondance and Cultural Exchange in Europe 1400-1700; vol. 4: Forging European Identities 1400-1700, Cambridge 2007.

50 Bernd RoECK, Introduction, dans: MuChEMBLED (dir.), Forging European Identities (voir n. 49), p. 3.

51 Peter BURKE, Kultureller Austausch, dans: ID., Kultureller Austausch, Francfort/M. 2000, p. 940.

52 ROECK, Introduction (voir n. 50), p. 2-4. 


\section{LES ÉLÉMENTS FONDAMENTAUX DES TRANSFERTS CULTURELS}

La grande variété des notions utilisées dans les différentes sciences sociales pour désigner, concevoir et distinguer les situations de contact intra-, inter- et transculturel, témoigne de la difficulté de proposer un cadre notionnel et méthodologique adéquat pour rendre compte de ces faits complexes. Cette diversité, que nous nous sommes efforcés de présenter, tout du moins dans ces principales notions, montre néanmoins la nécessité d'une redéfinition susceptible d'adapter la notion de transfert culturel et ses usages aux spécificités historiques de l'espace méditerranéen.

Ainsi, on considère que cette notion de transfert culturel, loin d'être restreinte à un cadre national ou thématique donné, peut désigner tout processus mettant en œuvre une multiplicité d'actions qui initient, encadrent et conditionnent la mobilité d'un bien culturel dans l'espace, le temps et le cadre socioculturel. Ce bien culturel provient d'un "autre«, dont les déterminants socioculturels et identitaires peuvent varier. Dans le présent article, nous entendons employer la notion d'espaces dans une acception large (géographique, temporelle et socioculturelle).

Pour concrétiser cette définition et afin de pouvoir expliquer les phénomènes liés aux transferts culturels, il semble utile d'introduire un exemple parlant comme base de réflexion. Les phénomènes étudiés dans ce chapitre seront principalement éclairés à partir de ce cas. D'autres exemples seront également analysés pour en démontrer les variations.

Dans un chapitre sur le Maghreb, al-Bakrī, géographe d'al-Andalus à qui l'on doit le »Livre des itinéraires et des royaumes«, rédigé aux environs de 460/1068, mentionne une matière première non identifiée et sa transformation symbolique au cours de son passage du Maghreb vers Constantinople via le nord de l'Espagne ${ }^{53}$ :

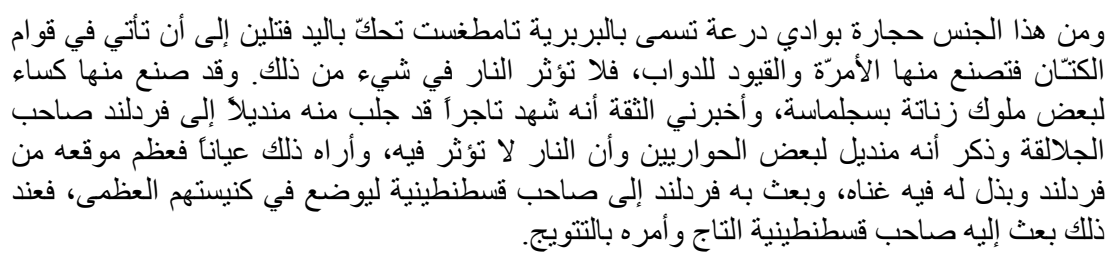

Et de cette nature, [il y a] une pierre dans le Wādī Dar'a, appelée Tāmațgust dans la langue des Berbères. Elle est polie à la main et ainsi, elle devient douce comme le lin. On l'utilise pour produire des harnais et des rênes pour le bétail. Elle [la matière] n'est pas inflammable. On l'avait utilisée pour fabriquer les vêtements de quelques-uns des chefs de [la tribu] Zanāta à Siğilmāsa. Il [le jurisconsulte 'Abd al-Malik] m'a confié qu'il avait vu un marchand qui avait apporté un mindīl [couvre-chef ou voile] ${ }^{54}$, produit de cette matière, à Ferdinand (Fardaland), roi de Galice, lui

53 Al-Bakrī, kitāb al-masālik wa 'l-mamālik, § 1469, éd. A. P. van LEEUwEN, A. FERRE, Carthage 1992, p. 878.

${ }^{54}$ Le mot »mindīl « ou »mandīl« peut recouvrir plusieurs sens. Dans les principaux dictionnaires arabes médiévaux, il est employé le plus souvent pour désigner une pièce de tissu utilisée 
mentionnant que le couvre-chef avait appartenu à l'un des apôtres et que le feu ne pourrait pas l'affecter. Quand il lui en fit la démonstration, l'estime de Ferdinand pour lui augmenta considérablement et le roi lui donna beaucoup d'argent. Ferdinand envoya le mindīl au maître de Constantinople afin qu'il place le voile dans leur église principale. C'est ainsi que le maitre de Constantinople envoya à Ferdinand une couronne et lui ordonna de se faire couronner [trad. FranceMed].

Dans cet exemple, l'objet en question est un voile issu d'un matériau ininflammable. Cet objet est tiré de son contexte original par un marchand avisé à propos duquel on n'a guère d'informations en dehors du fait qu'il était en contact avec un jurisconsulte musulman et qu'il semble avoir beaucoup voyagé entre les communautés musulmanes et chrétiennes d'Espagne. Ni son origine ni son obédience religieuse ne sont connues. Conscient de l'intérêt des chrétiens pour des objets aux propriétés miraculeuses provenant de l'entourage du Christ et de ses apôtres, il voit dans ce matériau un moyen de développer une saffaire ‘ qui motive par la suite ses actions. Adaptant le voile aux croyances crédules des chrétiens, il le réemploie comme marchandise à connotation sacrée en l'offrant et finalement en le vendant à Ferdinand de Galice, qui acquiert un objet dont il ne connaît pas le contexte d'origine. Ferdinand obtient un voile vendu en tant que relique chrétienne sainte et qui possède par conséquent un contenu symbolique et des qualités matérielles exceptionnelles. Dans un second temps, et sans effacer le contenu symbolique attribué au voile par le marchand, Ferdinand y ajoute une nouvelle dimension, le transformant en cadeau diplomatique pour le >maître de Constantinopleく, à savoir l'empereur byzantin. L'objet est alors envoyé de l'autre côté de la Méditerranée, servant de >capital politique ‘ dans un échange diplomatique. Selon alBakrī, le transfert de ce simple voile n'a pas seulement enrichi et rehaussé la réputation d'un marchand dans les cercles chrétiens et musulmans, mais il a aussi fourni une simportanteく relique à la principale église de Constantinople et pourvu le souverain de Galice d'une couronne royale offerte par l'empereur de Byzance.

Il est difficile d'interpréter la signification réelle de cette histoire dont l'authenticité historique, bien que secondaire dans ce contexte, peut sérieusement être remise en cause ${ }^{55}$. Cependant, cet exemple non seulement prouve la difficulté à recons-

comme couvre-chef ou comme voile. Le terme est utilisé également dans le sens de serviette ou de pièce de tissu servant à se draper. Selon David JACOBY, Silk Economics and Cross-Cultural Artistic Interaction. Byzantium, the Muslim World, and the Christian West, dans: Dumbarton Oaks Papers 58 (2004), p. 197-240, il proviendrait du grec byzantin, p. 221-222. Les sens »couvre-chef « ou »voile« sont les plus plausibles dans notre cas.

55 Cependant, elle peut refléter certains aspects des développements politiques de l'Espagne du Nord, à savoir la consolidation d'un royaume de Castille et de León unifiés sous la bannière de Ferdinand $\mathrm{I}^{\text {er }}$. Selon certains chercheurs espagnols, Ferdinand $\mathrm{I}^{\text {er }}$ est responsable de l'introduction du titre d'imperator Hispaniae, qui était supposé démontrer son nouveau statut de souverain de plusieurs regna. Voir Ramon MENÉnDEZ PIDAL, El imperio hispánico y los cinco reinos. Dos épocas en las estructura política de España, Madrid 1950, p. 86-94; Alfonso SÁNCHEZ CANDEIRA, Castilla y León en el siglo XI. Estudio del reinado de Fernando I, Madrid 1999, p. 121-122; Manuel ÁlVAREZ-VALDÉS Y VALDÉS, La extranjera en la historia del derecho español, Oviedo 1992, p. 148. Cette hypothèse est sérieusement remise en question par Margaret Mary CullinAn, Imperator Hispaniae. The Genesis of Spain, PhD thesis, City University, New York 1975, p. 156. Voir néanmoins p. 156, n. 66, où Cullinan mentionne plusieurs 
truire un processus de transfert culturel, mais il démontre également que les transferts culturels sont composés de plusieurs éléments constitutifs: l'objet transféré en tant que tel, les espaces dans lesquels il est transféré, et les acteurs qui - à l'échelle microhistorique - fonctionnent comme >stimulants` de ce transfert.

\section{OBJETS ET ESPACES}

L'objet du transfert peut concerner tout bien culturel. S'il n'est pas indispensable d'en fournir une énumération qui ne peut qu'être fastidieuse et surtout incomplète, il est nécessaire de classer les objets transférables selon trois catégories principales: leur matérialité, leur mutabilité et leur mobilité.

Les objets transférables sont de nature matérielle ou immatérielle. Matières premières et artefacts, plantes et animaux, et même les êtres humains peuvent être des objets matériels transférables. En revanche, le monde des idées - la pensée religieuse, politique, philosophique, les savoirs, les savoir-faire-, mais aussi les émotions, les perceptions et les expériences esthétiques, ainsi que les structures sociales, les modes de vie, les rituels, etc., renvoient aux objets immatériels transférables.

Cette classification primaire demeure théorique car il est évident que les deux catégories sont généralement imbriquées. Le transfert d'un objet >matériel implique le plus souvent la transmission d'éléments immatériels concernant sa valeur symbolique ou ses aspects fonctionnels. En reprenant l'exemple du voile mentionné par al-Bakrī, il est évident que son contenu symbolique était au moins aussi important que ses caractéristiques matérielles. La transmission vers l'Occident latin de l'astrolabe, instrument de mesure des positions géographiques et de la hauteur des astres, ne peut de même être réduite à une transmission physique car elle implique également la transmission de faits abstraits, comme l'imaginaire mathématique et l'expérience du corps ${ }^{56}$. Cette intrication du matériel et de l'immatériel est encore plus visible dans le cas du jeu d'échecs qui a été transféré depuis l'Inde ( $v^{\mathrm{e}}$ siècle) jusqu'à l'Europe occidentale ( $\mathrm{XI}^{\mathrm{e}}$ siècle) par le biais du monde musulman. Il est évident qu'il était nécessaire de

références extérieures à Ferdinand en tant qu'imperator. La description des échanges diplomatiques entre Byzance et Ferdinand semble quant à elle hautement improbable et ne trouve aucun écho dans la littérature secondaire sur le sujet. Le marchand, qui ne mentionne jamais ses sources d'informations, peut avoir inventé cette histoire pour être en vue et recevoir les éloges des musulmans exultant devant son astucieux exploit. En dehors de faire l'effort de garantir l'authenticité de cette annecdote en évoquant le jurisconsulte 'Abd al-Malik, al-Bakrī ne commente pas l'histoire qui s'achève par une autre référence au matériau miraculeux dans un contexte différent. Puisqu'il n'utilise pas l'histoire pour tourner en dérision la crédulité des chrétiens ou pour louer la sagacité du marchand, on ne peut tenir pour sûr qu'il a inséré l'histoire dans l'intention d'activement promouvoir une image négative des voisins chrétiens du nord d'al-Andalus.

56 Voir à ce propos l'étude d'Arianna BORRELLI, Aspects of the Astrolabe. Architectonica ratio in tenth- and eleventh-century Europe, Stuttgart 2008 (Sudhoffs Archiv, cah. 57). 
transmettre non seulement l'objet matériel, mais aussi les règles du jeu ${ }^{57}$. Un autre exemple nous est fourni par l'étude de Mohamed Ouerfelli sur la diffusion du sucre en Méditerranée. Dans ce cas, la transmission a une dimension abstraite qui va beaucoup plus loin que le simple acte de diffuser une marchandise dans le cadre de l'économie méditerranéenne. La transmission physique est fortement liée à la transmission du savoir, notamment concernant les qualités, les usages et les techniques de production du sucre 58 .

Par ailleurs, il faut se rendre compte que le transfert d'un >objet immatériel« implique le plus souvent la transmission d'éléments matériels. La diffusion des informations se fait, par exemple, oralement ou par écrit. Elle est donc dépendante d'un vecteur physique comme la voix ou un manuscrit. Ainsi, l'auteur al-Mas'ū dì nous rapporte qu'il eut accès, en 337/947 à al-Fusțāt, en Égypte, à des informations concernant les Francs. Ces données étaient véhiculées par une chronique offerte par l'évêque de Gérone, Godemar, au futur al-Hakam II, à l'époque héritier présomptif du calife de Cordoue, 'Abd ar-Raḥmān IIII59. Cette chronique est un objet matériel: un livre ou un rouleau produit à un certain moment dans un certain lieu et fonctionnant comme vecteur d'informations. Il est très difficile de déterminer exactement la façon dont le texte est arrivé en Égypte et par quelles mains il est passé. De même, il est complexe de savoir combien de fois il a été reproduit, s'il a été écrit à l'origine en arabe ou traduit, et il est par conséquent difficile d'en déterminer le moment de sa traduction (avant ou après sa présentation à al-Hakam). Il semble cependant relativement improbable qu'alMas'ūdī ait directement eu accès au manuscrit original offert au souverain. Il est probable que l'information soit passée d'un vecteur physique à un autre, lors de son transport physique, ou lorsqu'il fut compilé, copié, traduit, etc. En outre, il semble évident que le texte a été assimilé intellectuellement et reproduit à une ou plusieurs reprises sous une forme écrite et probablement orale.

Ce passage d'un vecteur physique à un autre nous conduit à une deuxième caractéristique de nombreux objets transférables, à savoir leur mutabilité. Il est évident que tous les objets ne sont pas soumis aux mêmes modes et degrés de transformation. Notre exemple de référence nous montre la façon dont une simple matière première se transforme en un voile adoptant successivement le statut de marchandise, de relique chrétienne et de cadeau diplomatique. Une fois créé, l'objet matériel, qui paraît relativement immuable, devient le vecteur de valeurs symboliques changeantes.

57 UMR 5648 (dir.), Pays d'islam et monde latin $\mathrm{X}^{\mathrm{e}}-\mathrm{XIII}^{\mathrm{e}}$ siècle, Lyon 2000 (Collection d'histoire et d'archéologie médiévales, 8), p. 277-281; Michel PASTOUREAU, Une histoire symbolique du Moyen Âge occidental, Paris 2004, p. 269-291 surtout p. 282-284; Olivia Remie CONSTABLE, Chess and Courtly Culture in Medieval Castile: The »Libro de Ajedrez« of Alfonso X, el Sabio, dans: Speculum 82/2 (2007), p. 301-347.

58 Mohamed OUERFELLI, Le sucre. Production, commercialisation et usages dans la Méditerranée médiévale, Leyde 2008 (The medieval Mediterranean, 71), p. 503-539.

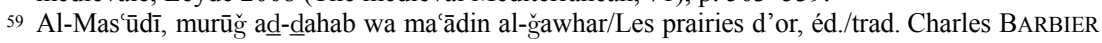
de Meynard, Abel Pavet de Courteille, Charles Pellat, vol. 2, §912, Beyrouth 1966/Paris 1965, p. 146 (éd. arabe), p. 344 (trad. française). 
La Grande Mosquée des Omeyyades de Damas nous en fournit un autre exemple. Le bâtiment, tout d'abord temple dédié à Jupiter, fut, à la suite à la christianisation de l'Empire romain, transformé en église ${ }^{60}$. Après la conquête arabe du VII siècle, une première moitié de l'édifice fut utilisée comme lieu de prière par les musulmans. Puis, en 85/705, sous le règne du calife al-Walīd b. 'Abd al-Malik (mort en 96/715), elle fut intégralement convertie en grande mosquée ${ }^{61}$. On peut ainsi souligner que la transformation de cet édifice est équivalente à son transfert. La valeur symbolique du bâtiment a changé avec la réutilisation et la modification des structures et des éléments architectoniques (chapiteaux, colonnes, blocs de pierres taillés, etc.), mais surtout avec la mutation de son cadre social. Bien que l'édifice continuât de remplir une fonction de culte, il n'était plus le même en raison de sa structure, de sa forme et de son cadre social.

De même, au cours de sa diffusion de l'Inde ( $\mathrm{V}^{\mathrm{e}}$ siècle) à l'Europe occidentale (XI ${ }^{\mathrm{e}}$ siècle), le jeu d'échecs a naturellement subi, non seulement dans ses règles mais aussi dans ses composantes, une longue et profonde adaptation. Celle-ci se manifeste dans la métamorphose du vizir en reine, de l'éléphant en dauphin puis en fou, du char en tour, etc. ${ }^{62}$

Un autre cas spécifique de la mutabilité d'un objet transférable nous est fourni par l'analyse des croisades. Envisagées en tant que transferts culturels, les croisades peuvent être interprétées comme un transfert d'agression dont résultent de nombreux

${ }^{60}$ La date de la transformation n'est pas connue. Il semble que le temple ait été transformé sous domination byzantine. Voir Klaus S. FREYBERGER, Das Heiligtum des Jupiter Damaszenus. Ein städtischer Kultbau lokaler Prägung dans: Mamoun FAnSA, Heinz GAUBE, Jens Windelberg (dir.), Damaskus - Aleppo: 5000 Jahre Stadtentwicklung in Syrien, Mayence 2000 (Archäologische Mitteilungen aus Nordwestdeutschland, cah. 28), p. 216-217.

61 Al 'Umarī, masālik al-abșār fī mamālik al-amșār, éd. Ahmad Z̄̄Kī BĀŠA, Le Caire 1924, vol. 1, p. 178-203; Muhammad Muțī AL-ḤĀFIẒ (dir.), al-ğāmi` al-ummawī bi Dimašq. nuṣụ̣̄ li-Ibn Ğubayr wa al-'Umarī wa an-Nu'aymī, Damas, Beyrouth 1985. Sur l'histoire de l'édifice en général et sur sa transformation voir entre autres: Karl WULZINGER, Carl WATZINGER, Damaskus. Die antike Stadt, Berlin, Leipzig 1921 (Wissenschaftliche Veröffentlichungen des DeutschTürkischen Denkmalschutzkommandos, 4); Karl WulzINGER, Damaskus. Die islamische Stadt, Berlin, Leipzig 1924; Jean SAUVAGET, Les monuments historiques de Damas, Beyrouth 1932; Keppel A. C. CRESWELl, Early Muslim Architecture, vol. 1: Umayyads, Oxford ${ }^{2}$ 1962; Oleg GraBAR, La Grande Mosquée de Damas et les origines architecturales de la mosquée, dans: Bibliothèque des cahiers archéologiques 2 (1968), p. 107-114; Stefan FREYBERGER, Untersuchungen zur Baugeschichte des Jupiter-Heiligtums in Damaskus, dans: Damaszener Mitteilungen 4 (1989), p. 61-86; Ernest WILL, Damas antique, dans: Syria 71 (1994), p. 1-43; Klaus Peter HAase, Die Grosse Moschee von Damaskus, dans: FANSA, GAUBE, WindELBERG (dir.), Damaskus - Aleppo (voir n. 60), p. 218-227; Finbarr B. FLOOD, The Great Mosque of Damascus: Studies on the Making of an Umayyad Visual Culture, Leyde 2001 (Islamic history and civilization, 33).

62 UMR 5648 (dir.), Pays d'islam et monde latin (voir n. 57), p. 277-281; Pastoureau, Une histoire symbolique du Moyen Âge (voir n. 57), p. 269-291; CONSTABLE, Chess and Courtly Culture (voir n. 57), p. 301-347; Hans HOLLÄNDER, Ein Spiel aus dem Osten, dans: Odilo ENGELS, Peter SCHREINER (dir.), Die Begegnung des Westens mit dem Osten. Kongreßakten des 4. Symposions des Mediävistenverbandes in Köln 1991 aus Anlaß des 1000. Todesjahres der Kaiserin Theophanu, Sigmaringen 1993 (Kongreßakten des 4. Symposions des Mediävistenverbandes, 4), p. 389-416. 
transferts secondaires. Ceux-ci se déclinent en transferts >positifs« de biens matériels, savoirs et savoir-faire techniques et artistiques, ou en transferts >négatifs`d'images, stéréotypes et formes variables de la réception de l'»autre«. L'agression transférée par la première croisade a rapidement engendré plusieurs formes de réaction interdépendantes. Tout d'abord, elle a entraîné l'engagement des élites juridico-religieuses dans l'appel au ğihād contre les croisés. Cet engagement s'exprime dans quelques traités sur le ğihād, notamment dans celui de 'Alī b. Țāhir b. Ğa'far as-Sulamī (m. 500/1107) et du secrétaire de Saladin, Abū 'l-Maḥāsin Yūsuf b. Šaddād (m. 631/1234)63. Dans ces traités sont développées des consignes adressées aux musulmans pour lutter contre les infidèles et gérer la situation issue de l'agression croisée. Cette dernière entraîne aussi une réaction des pouvoirs politiques qui se manifeste dans le durcissement des autorités politiques à l'égard des chrétiens d'Orient, comme par exemple lors de l'assaut d'Alep par les Francs en 517/1124, quand le gouverneur d'Alep, Ibn al-Haššāb, fit transformer toutes les églises en mosquées ${ }^{64}$. L'agression croisée trouve également un écho dans la mise en valeur de l'idéologie du ğihäd, à l'instar du programme politique de Nūr ad-Dīn (541/1147-569/1174). Du côté latino-chrétien, cette riposte musulmane a pu engendrer un ensemble de réactions institutionnelles, dont l'apparition des ordres militaires à partir du début du XII ${ }^{\mathrm{e}}$ siècle ${ }^{65}$. Cette mutabilité, qui prend dans ce cas la forme de la >traduction`, montre la façon dont un objet immatériel, en l'occurrence l'agression des croisés, se transforme en une contre-réaction idéologique qui, à son tour, induit des mesures concrètes.

La mobilité est une caractéristique inhérente à tout bien (>objet`) matériel ou immatériel qui est transmis pendant le transfert culturel au sein des espaces géographique, temporel et socioculturel. Dans notre exemple de référence, le voile voyage physiquement du Maghreb vers le nord de l'Espagne puis Constantinople. Ce voyage s'étendant dans le temps implique alors une dimension chronologique. Finalement, on peut noter que le voile >gravit l'échelle sociale` depuis une origine plutôt humble en tant que marchandise ordinaire dans son lieu de production, jusqu'à acquérir une valeur économique, spirituelle et politique de relique insigne dans un contexte ibérique et byzantin. Par conséquent, il existe aussi une dimension sociale à ce processus de transmission.

La plupart des objets mentionnés ci-dessus - la chronique franque utilisée par alMas'ūdī en Égypte, le sucre, l'astrolabe, le jeu d'échecs, l'agression dans un contexte d'expansion militaire - sont transférables d'un lieu géographique à un autre. On peut néanmoins rencontrer des objets qui échappent plus ou moins à cette caractéristique:

63 Suhayl ZAKKAR, arba'at kutub fî̀ 'l-ğihād min 'așr al-ḥurūb aṣ-ṣalībīya, Damas 2007.

${ }^{64}$ Ibn al-'Adīm, bug̉yat aț-țalab fi tārīh Halab, vol. 1, éd. Suhayl ZAKKĀR, Damas 1988, p. 62; Emmanuel SivAN, L'islam et la croisade. Idéologie et propagande dans les réactions musulmanes aux croisades, Paris 1968, p. 43.

65 Michel BALARD, Les Latins en Orient $\mathrm{XI}^{\mathrm{e}}-\mathrm{XV}^{\mathrm{e}}$ siècle, Paris 2006, p. 115-120; Nicolaus HeUTGER, Die Ritterorden im Heiligen Land: Die Hospitäler und Ordensgemeinschaften, dans: Die Kreuzzüge, Mayence 2004, p. 137-153; Alain DEMURgER, Chevalier du Christ. Les ordres religieux-militaires au Moyen Âge $\left(\mathrm{XI}^{\mathrm{e}}-\mathrm{XVI}^{\mathrm{e}}\right.$ siècle), Paris 2002; Alan G. FOREY, The Military Orders. From the Twelth to the Early Fourteenth Centuries, Londres 1992. 
malgré l'apport d'éléments nouveaux et quelques modifications à l'intérieur de l'édifice, les structures de la Grande Mosquée des Omeyyades de Damas n'ont pas été transférées dans l'espace, mais d'une époque à l'autre.

L'étude des transferts dans le temps nous permet d'analyser le voyage temporel d'un bien culturel. La chronique franque utilisée par al-Mas'ūdī en 336/947 en fournit un exemple. L'information selon laquelle le roi franc Clovis s'était converti au christianisme sous l'influence probable de sa femme à la fin $d u \mathrm{~V}^{\mathrm{e}}$ ou au début $\mathrm{du} \mathrm{VI}^{\mathrm{e}}$ siècle nous est fournie par Grégoire de Tours à la fin du $\mathrm{VI}^{\mathrm{e}}$ siècle, soit plus de 250 ans avant que l'information soit transmise et devienne accessible à al-Mas'ūdī ${ }^{6} 6$. Lu par al-Bakrī $\mathrm{au} \mathrm{XI} \mathrm{e}^{\mathrm{e}}$ siècle puis an-Nuwayrī au XIV $\mathrm{e}^{\mathrm{e}}$ siècle et par nous aujourd'hui, les informations contenues dans cette chronique étaient et sont transmises par différents canaux à un futur indéterminé67.

Matérialité, mutabilité et mobilité d'un objet transférable sont donc d'une grande importance en ce sens qu'elles influencent considérablement la nature d'un quelconque transfert. Les acteurs qui forment le lien entre sobjets transférables< et espaces constituent une autre composante fondamentale de tout transfert.

\section{ACTEURS}

On peut définir un acteur des transferts culturels comme toute personne, tout groupe ou toute institution agissant, volontairement ou involontairement, dans le but de transférer un bien culturel dans l'espace géographique, le temps et le cadre socioculturel. Comme cela a déjà été évoqué auparavant à propos de la matérialité des >objets transférables<, des êtres peuvent subir des transferts et être aussi considérés - dans certains cas spécifiques - comme des `biens culturels` qui, en tant qu'acteurs, sont capables d'influencer ces mêmes processus ${ }^{68}$. Il faut aussi s'interroger sur la qualité d' 'acteur` que pourraient acquérir certains objets, et en particulier les images, hypothèse suggérée par le rôle prépondérant de l'image dans la société de communication contemporaine ${ }^{69}$. Il reste cependant difficile de leur reconnaître une véritable fonction d'>acteurく à part entière

66 Gregorius Turonensis, Libri decem II,29-31, éd. Bruno KRUSCH, Wilhelm LEVISON, Hanovre 1951 (Monumenta Germaniae Historica, Scriptores rerum Merovingicarum, 1/1), p. 74-78. Pour les discussions sur la date de conversion voir Daniel KÖNIG, Bekehrungsmotive. Untersuchungen zum Christianisierungsprozess im römischen Westreich und seinen romanischgermanischen Nachfolgern (4.-8. Jahrhundert), Husum 2008 (Historische Studien, 493), p. 175, n. 79 .

${ }^{67}$ Al-Bakrī, kitāb al-masālik wa 'l-mamālik (voir n. 53), § 567, p. 340; an-Nuwayrī, nihāyat alarab fī funūn al-adab, vol. 15, Le Caire s.a., p. 286.

68 Comme nous le montre la traite des esclaves, un phénomène régulier et bien répandu dans la Méditerranée médiévale, voir p.ex. l'œuvre de Charles VERLINDEN, L'esclavage dans l'Europe médiévale, 2 vol., Bruges 1955/1977.

69 Régis DURAND, Michel POIVERT, L'événement. Les images comme acteurs de l'histoire, Paris 2007. 
puisqu'elles constituent avant tout des supports ou médias qui véhiculent un message symbolique et une charge esthétique attribuée par leur concepteur ou leur émetteur ${ }^{70}$.

Parmi les diverses catégories d'acteurs, trois grands types ou rôles se distinguent. Tout d'abord l'émetteur initie le mouvement d'un bien culturel à travers l'espace, le temps et les contextes socioculturels. Vient ensuite l'intermédiaire, qui transporte et transmet l'objet d'un point à l'autre. Pour finir, le récepteur, à l'autre extrémité de l'opération du transfert, reçoit le bien transféré. Comme nous allons le voir par la suite, cette distinction de trois rôles différents, quoique probante a priori, ne peut suffire à expliquer une réalité beaucoup plus complexe qui empêche de définir un début et une fin d'un transfert et qui sera évoquée dans l'analyse des chaînes opératoires. Il suffit de souligner ici que ces trois types sont très étroitement liés les uns aux autres, et qu'un acteur unique peut être, simultanément ou alternativement, émetteur, intermédiaire et récepteur.

Ce propos peut être illustré par l'un des récits célèbres de la première croisade. La »Gesta francorum et aliorum Hierosolimitanorum «71 est composée par un soldat franc de la suite de Bohémond de Tarente, dont l'intervention en tant qu'acteur relève des trois types prédéfinis: récepteur, par son séjour en Orient qui lui a apporté nombre d'informations sur les lieux et le contexte de la première croisade, dont il fut un protagoniste; émetteur, par la rédaction de sa chronique; intermédiaire, par son témoignage qui devient une source d'informations pour d'autres historiographes ${ }^{72}$. Peu après, en France, Guibert de Nogent, dans ses »Gesta Dei per Francos $«{ }^{73}$, entreprend à son tour d'écrire une histoire de la croisade. À l'inverse du chroniqueur anonyme de la »Gesta«, Guibert de Nogent n'est pas un témoin direct des événements mais veut faire une œuvre d'historien ${ }^{74}$ et de moraliste ${ }^{75}$, et utilise pour cela un certain nombre de témoignages directs qu'il a pu recueillir, dont celui de la chronique anonyme. Guibert de

70 Jean-Claude SCHMiTT, Le corps des images. Essais sur la culture visuelle au Moyen Âge, Paris 2002; Hans BelTING, La vraie image. Croire aux images?, Paris 2004.

71 Gesta francorum et aliorum Hierosolimitanorum (latin-français). Histoire anonyme de la première croisade, éd. Louis BRÉHIER, Paris 1924 (Les classiques de l'histoire de France au Moyen Âge, 4), réédition 2007. Pour la traduction française: Chronique anonyme de la première croisade, trad. Aude MATIGNON, Paris 1998. Connue en France à partir des années 11051106 , elle constitue un rapport relativement circonstancié et succinct des différents événements et opérations, depuis l'appel de Clermont jusqu'à la bataille d'Ascalon le 12 août 1099.

72 Guillaume de Tyr se sert aussi de la chronique anonyme pour rédiger certaines parties de son histoire du royaume de Jérusalem. Guillaume de Tyr, Chronique, éd. Robert B. C. HuYgENS, Turnhout 1986 (Corpus Christianorum Continuatio Mediaevalis, 63-63A).

73 Guibert de Nogent, Gesta Dei per Francos, dans: Recueil des historiens occidentaux des croisades, vol. 4, Paris 1879, p. 113-264. Guibert de Nogent, Gesta dei per Francos et cinq autres textes, éd. Robert B. C. HuYgENS, Turnhout 2002 (Corpus Christianorum continuatio Mediaevalis, 97). Pour la traduction française: Guibert de Nogent, Geste de Dieu par les Francs. Histoire de la première croisade, trad. Monique-Cécile GARAND, Turnhout 1998.

74 Il applique pour cela la confrontation des sources écrites et entreprend de collecter un certain nombre de témoignages. On ne saurait alors dénombrer tous les intermédiaires intervenant entre les deux rédacteurs.

75 Guibert de Nogent ne cherche pas à écrire un exposé factuel de la croisade mais à déterminer un arrière plan moral au mouvement général. Pour l'œuvre de Guibert de Nogent, voir l'introduction de Monique-Cécile Garand, Geste de Dieu par les Francs (voir n. 73), p. 6-13. 
Nogent est donc un récepteur dans son emploi de la »Gesta Francorum« et d'autres témoignages qu'il a amassés; il est également un intermédiaire par sa propre chronique, qui permet de relayer les informations collectées ${ }^{76}$, mais aussi un émetteur par son approche individuelle, qui se manifeste dans sa contribution exégétique et théologique au récit de la croisade et à l'interprétation de la Terre sainte en général.

À première vue, et dans le cadre d'une analyse des transferts culturels, il semble inévitable de distinguer les différents types d'acteurs impliqués dans ces transferts par leur profession, leur fonction ou leur statut social. Les ambassadeurs, les traducteurs et interprètes, les marins, marchands, guerriers, mécènes, pèlerins, esclaves, minorités religieuses ou sociales seraient ainsi au centre de l'étude. Pourtant, dans le cadre d'une analyse phénoménologique, la plupart des acteurs impliqués dans ces processus se distinguent plus par leur aptitude, tout comme par leur degré d'implication et leur motivation, que par leur seule fonction ou leur seul statut social.

La capacité d'un acteur à entreprendre un transfert dépend, en premier lieu, de son aptitude. Dans l'exemple de référence, la vente du voile à Ferdinand de Galice n'aurait pu s'effectuer si le marchand n'avait pas été capable de créer un lien entre le Maghreb et l'Espagne chrétienne. Cette aptitude ne s'exprime pas seulement dans le fait qu'il pouvait véhiculer des marchandises d'une sphère culturelle à une autre, mais aussi dans sa connaissance de l'intérêt des chrétiens pour les reliques. À travers l'exemple de l'abbé de Cluny, Pierre le Vénérable, il est possible d'analyser l'aptitude d'un acteur à initier, promouvoir et effectuer un transfert. En 1141, Pierre le Vénérable commanda la première traduction latine du Coran. En tant que dirigeant d'une institution qui comptait parmi les plus riches et les plus influentes de l'Occident latin ${ }^{77}$, et après une rencontre avec l'imperator Hyspaniarum Alphonse VII, il lui était possible de mettre en œuvre les mesures adéquates afin de faciliter ce transfert. Dans son œuvre polémique »Contre la secte des sarrasins«, il se révèle initiateur et mécène de cette traduction. Sa mention du paiement des traducteurs atteste qu'il en était le commanditaire. Étant conscient, en tant que mécène, des défis linguistiques d'une telle traduction, il exigea la participation à la tâche d'un musulman appelé »Mahumeth «78. Néanmoins, les limites de son aptitude à contribuer à l'exécution d'une telle œuvre s'y reflètent également: son opuscule polémique est adressé directement aux »fils arabes d'Ismaël« qu'il voulait convaincre de la vérité du christianisme ${ }^{79}$. Cependant, Pierre le Vénérable savait qu'il avait besoin d'un traducteur car le public visé n'était pas capable de comprendre ses réflexions en latin ${ }^{80}$. Contrairement aux traducteurs qu'il a employés, il n'était pas lui-même doué des compétences linguistiques nécessaires pour exécuter une telle traduction. Il savait que s'il ne trouvait pas de traducteurs, il devrait se contenter du fait

76 Les informations qui appartiennent au cadre des biens immatériels.

77 Joachim Wollasch, Cluny. Licht der Welt, Zurich 1996, p. 225-316.

78 Petrus Venerabilis, Contra sectam Saracenorum, fol. D 180rd, éd. James KRITZECK, dans: ID., Peter the Venerable and Islam, Princeton 1964 (Princeton Oriental Studies, 23), p. 229: »Et ut translationi fides plenissima non deesset, nec quicquam fraude aliqua nostrorum notitiae subtrahi posset, Christianis interpretibus etiam Sarracenum adiunxi«.

79 Ibid., fol. D 180vs, p. 231: »Arabibus Hysmahelis filiis«.

80 Ibid., fol. D 180vs, p. 230. 
de pouvoir fournir les arguments aux chrétiens pour s'armer contre l'islam, en leur transmettant ainsi des >connaissances secondaires ${ }^{81}$. Quant à son aptitude comme acteur des transferts culturels, elle était limitée: Pierre le Vénérable n'avait qu'un rôle d'initiateur, de mécène et de transmetteur secondaire et se distinguait par conséquent des traducteurs impliqués dans le même processus. En somme, il est nécessaire de considérer que l'aptitude d'une personne à agir comme acteur des transferts culturels est fortement liée aux réseaux de chacun, aux moyens matériels qu'il a à sa disposition ainsi qu'à ses facultés intellectuelles. Concernant son degré d'implication dans la traduction du Coran, Pierre le Vénérable nous offre l'exemple d'un personnage qui, à cause de ses capacités linguistiques manquantes, n'est pas directement impliqué, et ce malgré ses efforts pour initier et fournir le cadre adéquat au travail des traducteurs. Ces derniers sont finalement les vrais exécuteurs de la traduction. Ce n'est qu'en tant qu'auteur transmettant des arguments contre l'islam aux lecteurs chrétiens dans sa polémique que l'abbé de Cluny joue le rôle d'un acteur direct.

Le cas d'Adelard de Bath nous offre un autre exemple de personnage montrant ce que l'on pourrait définir comme un degré d'implication fort. Ce moine bénédictin du début du XII ${ }^{\mathrm{e}}$ siècle entreprend, après une formation en France, une série de voyages qui le mènent jusqu'en Sicile et à Antioche. Sa connaissance de l'arabe et du grec lui permet de traduire un certain nombre de traités de mathématique et de philosophie, ainsi que la rédaction d'une somme fondée sur la science arabe, les »Quaestiones naturales seu physicae« (1105-1116). Ses traductions ainsi que ses sommes furent par la suite amplement réemployées. Adelard est initiateur d'un transfert en tant que savant et traducteur, mais aussi en tant que voyageur, puisqu'il s'est lui-même rendu dans différents pays pour amasser les connaissances qu'il a par la suite réutilisées pour écrire ses œuvres, dénotant ainsi une véritable curiosité à l'égard de la culture scientifique du monde musulman 82 .

Enfin, l'analyse des lettres entre deux frères, marchands vénitiens du $\mathrm{XV}^{\mathrm{e}}$ siècle, reflète une autre forme d'implication. Zuan Alvise Morosini, installé en Syrie, était responsable de la vente sur place de produits d'Occident et de la fourniture des marchandises pour le marché vénitien. Il décrit en détail le déroulement de ses affaires dans une correspondance destinée à son frère. Celui-ci demeure à Venise et s'occupe, à son tour, de vendre les produits envoyés d'Orient par son frère et de lui procurer en retour des marchandises destinées au marché syrien ${ }^{83}$. Dans ce cas, le transfert réciproque, de nature commerciale, repose sur l'interdépendance entre deux personnes qui participent au même processus, celui du commerce entre Venise et l'Orient. Cette interdépendance exige une activité de la part de deux acteurs qui sont dans un flux d'échanges quasiment permanents.

81 Ibid.

82 Voir Charles BuRnetT (dir.), Adelard of Bath. An English Scientist and Arabist of the Early Twelfth Century, London 1987 (Warburg Institute Surveys and Texts, 14).

83 Éric VALLET, Marchands vénitiens en Syrie à la fin du XV siècle. Pour l'honneur et le profit, Paris 1999, p. 8. 
Ni l'analyse de l'aptitude ni celle du degré d'implication d'un acteur n'expliquent pourquoi cet acteur décide de participer au transfert des biens culturels. Il apparaît donc nécessaire d'examiner sa motivation qui peut être regardée comme le stimulant principal de tout transfert. Il est possible d'attribuer une sorte de >motivation professionnelle ‘ à certains groupes afin de transmettre des biens culturels. Contrairement aux pèlerins, esclaves et autres personnes, les ambassadeurs, traducteurs et interprètes, marchands et marins impliqués dans le transport de marchandises, agissent comme intermédiaires professionnels. Leur but est de transmettre des biens matériels ou immatériels d'un côté à l'autre. L'exemple, fourni par al-Bakrī, du marchand inventant des histoires religieuses pour vendre un voile au roi Ferdinand de Galice démontre bien cette motivation professionnelle de nature économique. Une motivation comparable est évoquée par un certain Guillaume de Adae, au XIV ${ }^{\mathrm{e}}$ siècle, dans sa polémique contre les marchands italiens qui, pour le profit, vendaient aux musulmans des armes et autres matériaux de valeur stratégique malgré les interdictions de l'Église ${ }^{84}$. Il reprend de cette façon les interdictions du quatrième concile du Latran (1215), interdictions également mentionnées par Raymond de Penyafort ${ }^{85}$. Ce cas met en avant le fait que la motivation professionnelle d'échanger des biens peut être supérieure aux normes imposées par leurs propres autorités religieuses. Les sources nous permettent aussi de saisir d'autres groupes qui ne sont pas naturellement impliqués dans les processus d'échanges tout en étant intéressés pour des raisons >professionnelles à y prendre part. Pierre le Vénérable commanda la première traduction latine du Coran afin de connaître et comprendre l'islam, pour mieux en réfuter la doctrine ${ }^{86}$. Cette traduction ne s'inscrit pas automatiquement dans ses tâches en tant qu'abbé de Cluny, mais relève parfaitement de sa position d'ecclésiastique intéressé à défendre et promouvoir la foi chrétienne. Dans la même optique, beaucoup de savants occidentaux des XII ${ }^{\mathrm{e}}$ et XIII ${ }^{\mathrm{e}}$ siècles ont montré un vif intérêt pour l'acquisition des savoirs scientifiques grecs et arabes. Étienne d'Antioche va même jusqu'à fournir des informations sur les endroits où ce savoir et les traducteurs nécessaires pouvaient être trouvés ${ }^{87}$. Il faut cependant considérer que le simple intérêt scientifique peut aussi motiver des actions menant aux échan-

84 Guillelmus Adae, De modo Sarracenos extirpandi, dans: Recueil d'histoire des croisades. Documents arméniens, vol. 2, Paris 1906, p. 519-555, ici p. 523.

85 Concilium Lateranense IV (1215), § 71, dans: Joseph WoHLMUTH (dir.), Konzilien des Mittelalters. Vom ersten Laterankonzil (1123) bis zum fünften Laterankonzil (1512-1517), Paderborn 2000, p. 270, 2-9; Raymond de Penyafort, Summae, vol. 3: Responsiones ad dubitalia, chap. 1-5, éd. Xavier OCHOA, Aloysius DiEZ, Rome 1976-1978, p. 1024-1026 avec une référence au concile du Latran dans le chapitre 3, p. 1025.

86 Petrus Venerabilis, Contra sectam Saracenorum, D 180rd-D 180vs, éd. KRITZECK (voir n. 78), p. $228-230$.

87 Stephen of Antioch, Preface to »Breviarium«, éd. Charles BuRnetT, dans: Charles BuRnETT, Antioch as a Link between Arabic and Latin Culture in the Twelfth and Thirteenth Centuries, dans: Isabelle DraElants, Anne TiHON, Baudouin VAN DEN ABEEle (dir.), Occident et Proche-Orient: Contacts scientifiques au temps des croisades, Turnhout 2001 (Réminisciences, 5), p. 1-78, ici p. 38; voir Charles BURNETT, Humanism and Orientalism in the Translations from Arabic into Latin in the Middle Ages, dans: Andreas SPEer, Lydia Wegener (dir.), Wissen über Grenzen: Arabisches Wissen und lateinisches Mittelalter, Berlin 2006 (Miscellanea mediaevalia, 33), p. 22-31, et surtout p. 24. 
ges sans être nécessairement liées à la profession. Dans un chapitre de sa »Muqaddima«, où il traite du grand transfert des sciences grecques vers le monde arabo-musulman, Ibn Haldūn (m. 808/1406) attribue la quête des manuscrits mathématiques grecs par le calife abbasside al-Manșūr et des musulmans de son entourage à leur intérêt scientifique ( $f i$ ' $l$ - $\{l m \text { rag } b a)^{88}$. De même, il faut souligner qu'un transfert culturel n'est pas toujours le produit d'une motivation bien définie. Il peut naître d'une rencontre fortuite qui, de nouveau, engendre l'intérêt de partager une expérience particulière. Ainsi, lors de son passage à Tyr, Ibn Ğubayr (m. 613/1217) a pu observer un mariage franc dont il fait la description dans son récit de voyage ${ }^{89}$.

On pourrait encore multiplier les exemples montrant la diversité des aptitudes, des degrés d'implication et des motivations des différents acteurs. En étudiant les transferts culturels, il ne faut pas oublier qu'aucun transfert n'aurait eu lieu sans moteur ni stimulant. Comme nous l'avons vu, les acteurs des transferts culturels sont à considérer comme stimulants d'un premier ordre qui, à cause de leurs différentes motivations, initient, promeuvent et effectuent des transferts. Sur une échelle microhistorique, on pourrait illustrer ces différentes motivations en évoquant les intérêts économiques, politiques, scientifiques, idéologiques, et l'intérêt pour ce qui est différent, voire exotique, etc. Sur une échelle macrohistorique, on pourrait supposer - à première vue - que les transferts sont nés d'une situation de >déséquilibreく. Les exemples évoqués cidessus, tels que celui des traductions du grec en arabe $\mathrm{du} \mathrm{VIII}^{\mathrm{e}}$ au $\mathrm{X}^{\mathrm{e}}$ siècle, mais aussi celui de l'intérêt des savants latino-chrétiens comme Adelard de Bath pour les sciences rarabes` au XII ${ }^{\mathrm{e}}$ siècle, pourraient suggérer une telle interprétation. L'analyse approfondie des grands processus de traduction démontre néanmoins qu'une explication aussi simpliste ne tient pas compte de l'encadrement qui favorise l'émergence et le déroulement des processus d'une telle complexité ${ }^{0}$. Présenter les croisades comme résultat

88 Ibn Haldūn, tārīh, éd. Suhayl ZAKKĀR, Halīl ŠAḤ̄DA, vol. 1, Beyrouth 2000-2001, p. 632; Ibn Khaldūn, al-Muqaddimah III, 87-93, trad. Franz Rosenthal, vol. 1, New York 1958, p. 115-118. Il est évident qu'Ibn Hualdūn simplifie. Les stimulants du transfert des savoirs grecs à l'arabe furent beaucoup plus complexes. Voir O'Leary DE LACY, How Greek Science Passed to the Arabs, Londres ${ }^{2} 1951$; Richard WALZER, Greek into Arabic. Essays on Islamic Philosophy, Oxford 1962 (Oriental Studies, 1); Dimitri GuTAS, Greek Thought, Arabic Culture. The Graeco-Arabic Translation Movement in Baghdad and Early 'Abbāsid Society (2nd-4th/8th10th centuries), Londres 1998; Dimitri GuTAS, The Greek and Persian Background of Early Arabic Encyclopedism, dans: Gerhard ENDRESS (dir.), Organizing Knowledge. Encyclopaedic Activities in the Pre-eighteenth Century Islamic World, Leiden 2006 (Islamic Philosophy, Theology and Science, 61), p. 91-101.

89 Ibn Ğubayr, rihlat Ibn Ğubayr, Beyrouth [1964?], p. 278. Dans son récit de voyage, il a rassemblé des informations à travers ses propres observations sur les pays qu'il a visités, mais aussi à travers les renseignements des personnes qu'il a rencontrées pendant son périple.

90 Comme exemple des études qui tiennent en compte cette complexité, voir: GUTAS, Greek Thought (voir n. 88); Dag Nikolaus HASSE, The Social Conditions of the Arabic-(Hebrew-)Latin Translation Movements in Medieval Spain and in the Renaissance, dans: SPEER, WEGENER (dir.), Wissen über Grenzen (voir n. 87), p. 68-86. Par ailleurs, la notion de dette culturelle a été récemment au centre de débats passionnés entourant la publication du livre polémique de Sylvain GouguenHEIM, Aristote au Mont-Saint-Michel. Les racines grecques de l'Europe chrétienne, Paris 2008. Voir les critiques dans: Max LEJBOWICZ (dir.), L'Islam médiéval en terres chrétiennes. Science et idéologie, Villeneuve d'Ascq 2008 (Les savoirs mieux, 26); Philippe BüTTGEN, 
d'un déséquilibre politique, par exemple, ne serait pas seulement réducteur, mais induirait une interprétation culturaliste et idéologique contestable. La question du >déséquilibre ‘ peut être appréhendée d'une façon plus nuancée et constructive sous l'angle du >développement inégal< et la périphérisation qui lui est associée ${ }^{91}$. Le chapitre suivant, qui traite le déroulement potentiel des transferts culturels par l'analyse des chaînes opératoires, nous met en garde contre des interprétations trop hâtives.

\section{LES CHAÎNES OPÉRATOIRES - LE DÉROULEMENT DES TRANSFERTS CULTURELS}

Le transfert du voile nous offre un exemple de ce que l'on pourrait appeler une unité de transfert, à savoir un processus dont le commencement - le lieu de production du voile - et la fin - l'église majeure de Constantinople - semblent parfaitement définis. Néanmoins, et hormis le fait que le processus en question pourrait aisément être subdivisé en unités plus petites, on devrait considérer que le début et la fin d'un tel processus ne sont pas toujours facilement définissables. La production du voile peut être identifiée comme la première étape du processus de transmission en admettant que dans le cas d'un tel objet matériel - le transfert commence avec sa fabrication. Mais même ainsi, il semble superficiel de définir un début, puisque les artefacts sont toujours constitués de matières premières. En ce qui concerne la fin du processus, on ne sait pas ce qu'il advient du tissu, après qu'il fut placé dans l'église majeure de Constantinople. Supposant qu'il s'agit d'un objet réel, on pourrait librement supputer qu'il a été emmené à Venise après le sac de Constantinople en 600/1204, ou ajouté au trésor de Mehmet le conquérant en 856/1453...

C'est aussi tenu pour vrai pour les objets d'une nature plus abstraite. Comme déjà expliqué, la chronique franque employée par al-Mas'ūdī fut transportée de Gérone à

Alain de Libera, Marwan Rashed, Irène Rosier-CATACH (dir.), Les Grecs, les Arabes et nous. Enquête sur l'islamophobie savante, Paris 2009; Thomas RiCKLIN, Der Fall Gouguenheim, dans: Historische Zeitschrift 290 (2009), p. 119-135 [Recension de: Sylvain GoUGUENHEIM, Aristote au Mont-Saint-Michel. Les racines grecques de l'Europe chrétienne, Paris 2008].

91 Les notions de périphérisation et de développement inégal apparaissent dans des études qui reflètent des courants historiographiques différents. La question de la périphérisation de certaines régions méditerranéennes par rapport aux centres économiques de l'économie-monde de la fin du Moyen Âge et du début de l'époque moderne a été soulevée par Braudel ou Immanuel WALlerstein, Capitalisme et économie-monde: 1450-1640, Paris 1980. Un courant d'inspiration marxiste, représenté notamment par les travaux de Samir Amin, a mis en valeur la notion de développement inégal comme paradigme pour l'étude des origines du sousdéveloppement du tiers monde. Voir Samir Amin, Le développement inégal: essai sur les formations sociales du capitalisme périphérique, Paris 1973. Pour une approche du contexte méditerranéen médiéval et moderne sous cet angle, María Teresa PÉREZ PICAZO, Guy LEMEUNIER, P. SEgura (dir.), Desigualidad y dependencia. La periferización del Mediterráneo occidental (ss. XII-XIX), Murcie 1986, notamment la contribution de Denis MENJOT, La >periferización< del Mediterráneo occidental en la Edad Media (XI-XV), p. 42-53. 
Cordoue et de Cordoue à al-Fusțāt entre 328/939-940 et 336/94792. Comme dans le cas du voile, nous semblons être capables de définir un commencement et, tout du moins, une fin au processus de transfert. Les choses sont cependant plus complexes: le texte en question constitue le corpus d'informations formé de plusieurs composants plus petits qui ont été regroupés progressivement jusqu'à produire la compilation qui était accessible à al-Mas'ūdī. Il est difficile de définir exactement le moment de la création de cette compilation: tout d'abord, on doit prendre en compte le fait que le corpus d'information, reçu par al-Mas'ūdī contenait des éléments qui étaient déjà, à l'époque de ce dernier, vieux de plusieurs siècles - par exemple l'histoire de la conversion du roi franc Clovis. La compilation pourrait ainsi avoir été collationnée à Gérone ou à Cordoue en tant que série de notes produites au cours de la traduction du latin vers l'arabe, mais elle pourrait aussi avoir été réalisée en Égypte, puis transmise oralement à al-Mas'ūdī par la personne qui a lu puis traduit le texte. Utilisée notamment par des historiographes arabo-musulmans plus tardifs, l'information est encore à notre disposition aujourd'hui, ce qui montre que le processus de transfert n'est pas encore terminé93.

Ainsi, au lieu d'un processus clos de transfert avec un commencement et une fin définis, nous pouvons plus largement distinguer des unités de transfert qui constituent des étapes dans l'histoire des objets matériels ou immatériels. En subdivisant les unités de transfert, on peut distinguer les processus de transmission et de réception. La transmission englobe toute activité liée à la mobilité d'un objet transférable, tandis que la réception recouvre toute activité liée à l'intégration (inclus l'acceptation et le refus) d'un objet transféré. Il convient à présent de traiter des processus subordonnés à la transmission et la réception.

Lors d'une transmission, un objet peut subir des transformations dans la plupart des cas; ces transformations peuvent être le produit d'actions inconscientes ou conscientes: un scribe médiéval copiant un manuscrit va nécessairement introduire des altérations dans la forme et le contenu (p.ex. matériel, couleurs, dessins). La plus parfaite des copies n'est pas une reproduction à l'identique de l'original ${ }^{94}$. Dès qu'un émetteur exerce consciemment une influence sur un objet transférable, la transformation de ce dernier constitue un effet d'accommodation, à savoir une manipulation de l'objet en question selon les souhaits de l'émetteur. En règle générale, la transformation a toujours lieu dès que l'objet transférable en question doit être produit, assimilé ou reproduit en vue d'une transmission. Les sources fournissent de nombreux exemples: dans son traité théologique adressé aux sarrasins, Pierre le Vénérable expose clairement son souhait d'appeler les musulmans à se convertir à la foi chrétienne. Contrairement à beaucoup de chrétiens qui ont recours à la violence, il entend les mener sur le »chemin du salut« ( $a d$ salutem) en ayant recours au verbe, à la raison et à l'amour. En dotant l'arsenal chrétien (Christianum armarium) contre l'islam de nou-

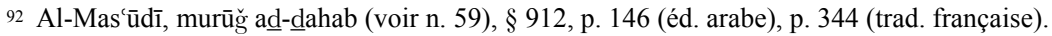

93 Al-Bakrī, kitāb al-masālik wa 'l-mamālik (voir n. 53), § 567, p. 340; an-Nuwayrī, nihāyat alarab fī funūn al-adab, vol. 15 (voir n. 67), p. 286.

94 Voir David JAmES, Early Islamic Spain. The History of Ibn Al-Qutiya, Londres 2009 (Culture and Civilization in the Middle East, 15), p. 18: »no handwritten text can be entirely free from scribal error, no matter how meticulous the copyist $\ll$. 
veaux éléments d'argumentation, Pierre le Vénérable choisit consciemment une méthode de communication dans l'espoir de gagner au moins quelques convertis, adaptant sa présentation du christianisme aux exigences d'un public musulman comme il l'imagine ${ }^{95}$. Un autre exemple de manipulation consciente est fourni par Matthaeus Parisiensis. Il rapporte une rumeur circulant en 1245 selon laquelle les sarrasins auraient empoisonné une grande quantité de poivre provenant d'Orient dans l'intention d'affaiblir la capacité de l'Europe occidentale à envoyer des croisés. Des hérauts transmirent des avertissements aux villes les plus importantes en France et en Angleterre bien que certains crussent, ajoute Matthaeus Parisiensis, que les marchands impliqués dans l'importation d'épices aient lancé cette rumeur afin de pouvoir vendre leurs anciens stocks ${ }^{96}$.

L'accommodation est intrinsèquement liée à l'audience envisagée. Ibn Rušd/ Averroès, dont les commentaires sur Aristote ont été largement diffusés pour être reçus, d'une façon ou d'une autre, par la majorité des écolâtres latins, n'a probablement jamais imaginé que son travail serait discuté au-delà du monde musulman. Sans aucun doute, son interprétation d'Aristote peut être vue comme une accommodation des idées d'Aristote qui provient de l'assimilation, de la reproduction et de l'analyse des œuvres de ce dernier. Cependant, le but de cette accommodation était d'expliquer Aristote aux princes gouvernants et aux intellectuels de son temps, non aux représentants de la scholastique latino-chrétienne ${ }^{97}$.

Le processus de transmission n'a pas nécessairement un effet sur l'émetteur. Les épées >franques`, par exemple, sont mentionnées et leurs mérites loués dans de nombreux textes arabo-musulmans. Bien que cela prouve que l'exportation d'un produit de qualité crée une certaine réputation, son existence n'affecte pas nécessairement directement le fabricant local ${ }^{98}$. Le capitaine génois qui transportait le voyageur musulman

95 Petrus Venerabilis, Contra sectam Saracenorum, prologus, éd. KRITZECK (voir n. 78), p. 230: »Quod si forte haec de qua agitur Scriptura aut interpretes non habuerit, aut translata non profuerit, habebit saltem Christianum armarium etiam adversus hos hostes arma, quibus aut se muniat, aut quibus, si forte ad certamen ventum fuerit, inimicos confodiat«. Liber primus, p. 231: »Aggredior, inquam, vos, non, ut nostri saepe faciunt, armis, sed verbis, non vi, sed ratione, non odio, sed amore... Hoc modo ego de innumeris et inter innumeros servos Christi minimus, vos diligo, diligens vobis scribo, scribens ad salutem invito«. Voir Norman DANIEL, The Arabs and Mediaeval Europe, Londres, New York ${ }^{2} 1986$, p. 242.

96 Matthaeus Parisiensis, Chronica majora, a. 1245, éd. Henry Richard LuARDS, vol. 4, Londres 1877, p. 490; cf. Matthew of Paris, History of England, a. 1245, trad. John A. GILES, vol. 2, Londres 1853, p. 118.

97 Lenn E. Goodman, Ibn Țufayl, dans: Seyyed Hossein NASR, Olivier LEAman (dir.), History of Islamic Philosophy, New York 1996 (Routledge History of World Philosophies, 1), p. 314. Sur l'œuvre d'Ibn Rušd et sa réception, voir Dominique URVOY, Averroès, les ambitions d'un intellectuel musulman, Paris 1998; André BAZZANA, Nicole BÉRIOU, Pierre GuICHARD, Averroès et l'averroïsme. Un itinéraire historique du Haut Atlas à Paris et à Padoue, Lyon 2005 (Collection d'histoire et d'archéologie médiévales, 16).

98 Ibn Hurradadibih, kitāb al-masālik wa 'l-mamālik, éd. DE GOEJE, Leiden 1889, p. 154; al-Bakrī, kitāb al-masālik wa 'l-mamālik (voir n. 53), § 1532, p. 914; cf. Robert HoYLAND, Brian GILMOUR (dir.), Medieval Islamic Swords and Swordmaking: Kindi's Treatise On Swords and Their Kinds (edition, translation, commentary), Cambridge 2006. 
Ibn Ğubayr depuis la côte syrienne jusqu'en Sicile en 579/1184 n'était pas affecté par le fait qu'il conduisait un pèlerin musulman sur son chemin de La Mecque vers alAndalus, même si cette action l'a fait passé à la postérité99. Comme nous l'avons déjà signalé, Ibn Rušd/Averroès n'a pas pu être conscient de l'influence qu'il a eu sur la pensée de nombreux occidentaux lorsqu'il s'est mis à expliquer et interpréter Aristote. Dans bien des cas, cependant, la transmission a des effets sur l'émetteur. L'exportation de bois et d'armes aux Égyptiens au XIV siècle contribuait à l'enrichissement des marchands issus des cités italiennes qui étaient férocement critiqués par Guillaume d'Adae pour cette raison. Cette activité controversée a entraîné, au sein des royaumes latins, des interdictions religieuses et des polémiques sur le fait qu'approvisionner les musulmans en matériel d'importance stratégique pouvait mettre en danger la sécurité de la chrétienté latine et le succès des croisades en Terre sainte ${ }^{100}$. En ce sens, l'acte de transmission a généré des réponses à l'intérieur de la société émettrice, sans nécessairement forcer les cités-états d'Italie à abandonner cette forme lucrative d'entreprise. Il est aussi possible d'imaginer qu'un acte de transmission affecte l'émetteur si le transfert entraîne un appauvrissement, par exemple à la suite du paiement d'un tribut ${ }^{101}$, ou de la perte du monopole sur un élément stratégique crucial qui influence l'équilibre des pouvoirs en situation de conflit ${ }^{102}$.

Bien plus que l'émetteur, le récepteur est affecté par la transmission. Au cours de la réception, un objet est reçu à un ou plusieurs >points d'arrivée`. La réception peut être active, impliquant la recherche d'un objet à transférer. Selon la soi-disant »Chronique de Frédégaire«, l'origine des Francs remonte à la maison royale de Troie ${ }^{103}$. Ce mythe d'origine créé au lendemain de la désintégration de l'Empire romain d'Occident peut être interprété comme un effort de construction d'une origine franque égale à celle des Romains à des fins de légitimation politique ${ }^{104}$. Dans d'autres cas, la réception est

99 Ibn Ğubayr, riḥlat (voir n. 89), p. 285.

${ }^{100}$ Concilium Lateranense IV (voir n. 85), § 71, p. 270, 2-9; Raymond de Penyafort, Responsiones ad dubitalia, chap. 1-5, éd. OCHOA, DIEZ (voir n. 85), p. 1024-1026, avec des références au synode du Latran de 1215 dans le chapitre 3, p. 1025; Guillelmus Adae, De modo Sarracenos extirpandi (voir n. 84), p. 523.

101 Voir l'exemple des tributs payés par les royaumes de taifas aux chrétiens dans la péninsule Ibérique au $\mathrm{XI}^{\mathrm{e}}$ siècle. Pierre GUICHARD, L'Espagne et la Sicile musulmanes aux $\mathrm{XI}^{\mathrm{e}}-$ $\mathrm{XII}^{\mathrm{e}}$ siècles, Lyon ${ }^{3} 2000$, p. $48-51$.

102 Voir l'exemple du feu grégeois, traité par Ekkehard EICKHOFF, Seekrieg und Seepolitik zwischen Islam und Abendland. Das Mittelmeer unter byzantinischer und arabischer Hegemonie (650-1040), Berlin 1966, p. 142-144.

${ }^{103}$ Chronicarum quae dicuntur Fredegarii scholastici libri IV cum continuationibus II,4-9, éd. Bruno KRUSCH, Hanovre 1888 (Monumenta Germaniae Historica, Scriptores rerum Merovingicarum, 2), p. 1-168, p. 45; ibid., III,2-9, p. 93-95.

${ }^{104}$ Helene HOMEYER, Beobachtungen zum Weiterleben der trojanischen Abstammungs- und Gründungssagen im Mittelalter, dans: Res publica litterarum 5 (1982), p. 93-123; František GRAUS, Troja und trojanische Herkunftssage im Mittelalter, dans: Willi ERZGRÄBER (dir.), Kontinuität und Transformation der Antike im Mittelalter, Sigmaringen 1989 (Veröffentlichung der Kongreßakten zum Freiburger Symposion des Mediävistenverbandes, 2), p. 25-43; Eugen EwIG, Troja und die Franken, dans: Rheinische Vierteljahresblätter 62 (1998), p. 1-16; Hans Hubert ANTON, Troja-Herkunft, origo gentis und die frühe Verfaßtheit der Franken in der gallisch-fränkischen Tradition des 5.-8. Jahrhunderts, dans: Mitteilungen des Österreichischen 
passive dans le sens où elle a été imposée de l'extérieur: la »Continuatio hispana« décrit les conditions de l'imposition d'un système fiscal sur les populations autochtones de la péninsule Ibérique après la conquête arabo-berbère au début du VIII ${ }^{\mathrm{e}}$ siècle $^{105}$.

S'ils ne sont pas refusés, les biens transférés sont toujours appropriés. L'appropriation entraîne l'acceptation des biens culturels ainsi que leur recontextualisation. Le Coran a tout d'abord été traduit en latin et ensuite transféré dans l'orbite intellectuelle de la chrétienté latine, lorsque des ecclésiastiques tels que Pierre le Vénérable ont vu la nécessité de comprendre l'islam pour mieux le combattre ${ }^{106}$. L'appropriation implique généralement la transformation, souvent même une adaptation consciente de l'objet reçu. La traduction latine du Coran, déjà évoquée, est pleine non seulement d'erreurs mais aussi de manipulations: les traducteurs se sont même permis de restructurer le livre saint de l'islam ${ }^{107}$. De plus, la traduction du Coran attribuait à celui-ci une fonction totalement différente de celle qu'il avait dans le monde musulman: non pas vénéré comme parole de Dieu, il était vu comme le message d'un faux prophète et par conséquent était employé comme réservoir d'arguments contre l'islam ${ }^{108}$. Cependant, la transformation de l'objet en question n'est pas nécessairement effectuée pendant l'appropriation, spécialement lorsqu'il s'agit d'objets physiques. On peut encore le voir dans l'étude de Mohamed Ouerfelli. Lorsque le sucre a été intégré dans la pratique pharmacologique et la cuisine locales de la Méditerranée médiévale, le processus d'appropriation a entraîné la modification du traitement médical et des habitudes alimentaires mais non de la matière première en elle-même ${ }^{109}$. En conséquence, la transformation d'un objet transmis peut, mais pas obligatoirement, prendre place pendant le processus d'appropriation. Il semble que les objets immatériels, qui doivent être intellectuellement assimilés et reproduits pendant la transmission, sont généralement plus susceptibles de subir des transformations. En revanche, les objets physiques semblent plus facilement transmissibles dans le temps et l'espace géographique sans changements majeurs.

Instituts für Geschichtsforschung 108 (2000), p. 1-30; Magali COUMERT, Origines des peuples et récits du haut Moyen Âge occidental (550-850), Paris 2007 (Collection des études augustiniennes/série Moyen Âge et Temps modernes, 42); Alheydis Plassmann, Origo gentis. Identitäts- und Legitimitätsstiftung in früh- und hochmittelalterlichen Herkunftserzählungen, Berlin 2006 (Orbis mediaevalis, 7), p. 188-191.

105 Continuatio hispana $\S 79$, éd. Theodor Mommsen, Berlin 1894 (Monumenta Germaniae Historica, Auctores Antiquissimi, 11), p. 356; ibid., § 80, p. 356.

106 Petrus Venerabilis, Contra sectam Saracenorum, prologus, chap. 15, éd. KRITZECK (voir n. 78), p. 228.

107 KRITZECK, Peter the Venerable and Islam (voir n. 78), p. 98; Ludwig HagemanN, Die erste lateinische Koranübersetzung - Mittel zur Verständigung zwischen Christen und Muslimen im Mittelalter?, dans: Albert ZIMMERMANN, Ingrid CRAMER-RUEGENBERG (dir.), Orientalische Kultur und europäisches Mittelalter, Berlin 1985 (Miscellanea mediaevalia, 17), p. 51-55; Thomas BuRman, Tafsī and Translation: Robert of Ketton, Mark of Toledo and Traditional Arabic Qurān Exegesis, dans: Speculum 73,3 (1998), p. 703-732, avec plus de bibliographie.

108 Ludwig VONES, Zwischen Kulturaustausch und religiöser Polemik. Von den Möglichkeiten und Grenzen christlich-muslimischer Verständigung zur Zeit des Petrus Venerabilis, dans: SPEER, WEGENER (dir.), Wissen über Grenzen (voir n. 87), p. 236.

109 OUERFELLI, Le sucre (voir n. 58), p. 503-660. 
La réception affecte toujours le récepteur: dans le cas d'un refus, l'entité réceptrice potentielle est privée des effets qui résulteraient de l'incorporation de l'élément externe. Ceci, par exemple, est ce que croient les deux clercs qui, selon la »Chronique d'Ernoul et de Bernhard le Trésorier«, ont sans succès essayé de convertir le sultan alMu'azzam au christianisme pendant la cinquième croisade. En raison de leur échec et de son refus de la »vraie foi«, son âme serait perdue pour Dieu ${ }^{110}$. Si le refus d'un objet culturel affecte le récepteur potentiel, son acceptation l'influence encore plus: différentes formes de conversion peuvent servir pour illustrer les effets produits par la réception et l'appropriation d'un système de croyances ou de l'un de ses aspects ${ }^{111}$. L'impact de l'introduction du sucre dans la Méditerranée médiévale se reflète dans l'évolution de la médecine et de la culture culinaire112. La réception de passages de l'histoire franque par al-Mas'ūdī produit la première présentation générale de l'histoire franque dans la littérature arabo-musulmane. Ainsi, réception et appropriation affectent clairement le récepteur et son environnement et le transforment.

\section{DIFFÉRENTES FORMES DES TRANSFERTS CULTURELS}

Tout cela peut suggérer qu'un modèle de l'émetteur-récepteur, élaboré à un certain degré, est applicable à des unités de transfert. C'est le cas dans l'anecdote d'al-Bakrī à propos du voile provenant du Maghreb: le marchand et Ferdinand de Galice transmettent activement et consciemment l'objet en question, fonctionnant comme des rémetteurs々. L'objet est tout d'abord reçu par Ferdinand de Galice, puis par l'empereur byzantin qui, à son tour, agit en tant que >récepteur`. Mais comme nous l'avons déjà démontré dans les passages traitant du phénomène d'accommodation, le transfert culturel peut se dérouler sans impliquer d'émetteur actif. En outre, notre développement sur les deux types de réception, passive et active, a montré que la transmission peut être déclenchée dans d'autres cas à l'initiative des récepteurs. Par conséquent, l'>émission`, processus d'envoyer activement un objet culturel d'un point vers une destination spécifique et connue, est un processus optionnel qui peut former une partie de la transmission mais ne constitue pas un élément indispensable d'un processus de transfert culturel. Un modèle simple d'émetteur-récepteur n'est alors pas applicable.

Pendant le voyage du voile d'al-Bakrī depuis le Maghreb jusqu'à Constantinople, plusieurs unités de transmission se sont succédé. En se concentrant sur l'aspect spatial, on peut distinguer le voyage du Maghreb vers le nord de l'Espagne et celui depuis le nord de l'Espagne jusqu'à Constantinople. Comme le processus de transmission ne

110 Chronique d'Ernoul et de Bernard le Trésorier, éd. Louis de MAS LATRIE, Paris 1871, p. 433: »Se vous ne volés croire, [disent il], nous renderons vostre ame à Diu, car nous vous disons por voir que se vous morés en ceste loi où vous estes, vos estes perdus, ne Dius n'ara mie vostre ame«; cf. John Tolan, Saint Francis and the Sultan. The Curious History of a ChristianMuslim Encounter, Oxford 2009, p. 40-48.

111 Pour le contexte de la christianisation de l'Europe occidentale de l'Antiquité tardive et du haut Moyen Âge, voir KÖNIG, Bekehrungsmotive (voir n. 66), p. 522-523.

112 OUERFELLI, Le sucre (voir n. 58), p. 503-659. 
concerne qu'un seul objet, il est possible de retracer la séquence des unités successives de transmission qui se sont construites les unes sur les autres.

Des séquences plus complexes caractérisent d'autres transferts. On trouve des cas où un contexte général sert de stimulant à différents transferts: le climat de confrontation entre pouvoirs musulmans et chrétiens après le début des expansions latines a engendré un net durcissement des rapports à l'égard des minorités, et progressivement, la détérioration significative de leurs conditions de vie. Les Mozarabes d'al-Andalus, par exemple, ont subi une série de déportations de la part des autorités almoravides, qui soupçonnaient leur allégeance aux pouvoirs chrétiens. C'est surtout à la suite de la campagne d'Alphonse le Batailleur en 1125-1126, que plusieurs d'entre eux sont déportés vers le Maroc, d'autres contraints à fuir vers les terres chrétiennes de la Péninsule ${ }^{113}$. En conséquence de ce déplacement, ils ont contribué au transfert de certains aspects de la culture mozarabe au Maghreb et en Espagne.

Mais des formes de transmission plus complexes ne sauraient être réduites à des `séquences linéaires`. L'exemple de deux frères vénitiens impliqués dans l'échange de marchandises entre un marché occidental autour de Venise et un marché oriental en Syrie fournit le cas d'un transfert quasiment permanent qui dépend de la réciprocité et de l'interdépendance des acteurs impliqués. D'une certaine manière, les unités de transmission sont plus ou moins fixées - même si les produits envoyés d'un côté à l'autre changent selon la dialectique de l'offre et de la demande caractéristique de toute activité commerciale. Ainsi, c'est la régularité qui caractérise la transmission et la réception de ces produits ${ }^{114}$. Dans d'autres cas, on peut discerner plusieurs unités de transmission concernant le même objet et qui sont répétées dans des sphères géographiques, temporelles ou sociales différentes. L'objet en question, et par extension, les unités de transmission peuvent être dupliqués, à l'instar du transfert d'idées, de coutumes, de techniques ou d'objets produits en masse. En retraçant la diffusion de la production du sucre, en analysant le déplacement des centres de production et la modification des habitudes de consommation d'une région à l'autre, Mohamed Ouerfelli a pu reconstruire la diffusion d'un produit consommé et son infrastructure ainsi que définir les principaux acteurs dans leurs divers cadres sociaux ${ }^{115}$. Il s'agit ici d'un processus de transmission sur un niveau macrohistorique qui pourrait être appelé »diffusion« ou »dissémination«.

\section{CONCLUSION}

Redéfinir le cadre conceptuel et les applications potentielles d'une notion aussi complexe et ambivalente que la notion de transferts culturels nécessite avant tout de se placer dans la continuité des différents concepts et grilles de lectures employés pour

113 Sur ce contexte particulier, Vincent LAGARDĖRE, Communautés mozarabes et pouvoir almoravide en 519h/1125 en al-Andalus, dans: Studia Islamica 67 (1988), p. 99-119.

114 VALLET, Marchands vénitiens en Syrie (voir n. 83), p. 8.

115 OUERFELLI, Le sucre (voir n. 58), p. 661-667. 
décrire et penser le champ des interactions culturelles. Il était ainsi indispensable de proposer une lecture historiographique des conditions de l'émergence et de la portée de notions phares, telle l'acculturation, le métissage et l'hybridité ou encore la traduction, avant d'aboutir à celle des transferts culturels. L'historique de ces différentes notions, situées à la croisée de l'histoire et des autres sciences sociales (principalement l'anthropologie et la sociologie), a révélé les tensions inhérentes à leurs contextes de genèse et encore sous-jacentes dans leurs domaines d'application. La prégnance de la situation coloniale et de ses implications sur la culture des minorités est ainsi imprimée dans la plupart de ces notions (acculturation et métissage/hybridité notamment). Envisager les liens intra-, inter- et transculturels sous l'angle des transferts culturels, offre à cet égard une certaine neutralité et un passé moins encombrant. Il a fallu néanmoins revenir, là aussi, sur l'émergence et la spécificité du champ notionnel des transferts culturels en tant que catégorie dominée, notamment dans le paysage de l'histoire culturelle franco-allemande, par les travaux de M. Espagne et d'autres chercheurs.

Transposer la notion dans le domaine méditerranéen médiéval passait donc par une nécessaire redéfinition, qu'il a fallu penser non seulement comme une juxtaposition d'éléments fondamentaux constitutifs de tout acte de transfert culturel, mais aussi comme un processus dynamique et multidimensionnel. Une approche phénoménologique de la question nous a semblé ainsi un bon moyen pour restituer les différents cadres qui caractérisent les processus de transferts culturels et les chaînes opératoires qui les composent. Malgré l'aspect fragmentaire du matériel documentaire disponible qui ne permet guère de suivre tous les moments d'un processus de transfert, un cadre hypothétique et expérimental a pu être suggéré à l'aide d'exemples variés, tous issus du contexte méditerranéen.

Les transferts culturels sont essentiellement fondés sur deux processus majeurs: la transmission et la réception. La transmission peut revêtir une dimension spatiale, temporelle et socioculturelle, et prendre une forme physique ou abstraite incluant de la sorte tous les types de communication visuelle, sensorielle, orale ou écrite. Ce n'est que dans certains cas que nous pouvons appliquer le modèle simple de l'émetteurrécepteur au processus de transmission. Celle-ci entraîne le plus souvent, mais pas nécessairement, la transformation d'un objet transmis pendant son altération inconsciente ou son accommodation consciente. Dans certains cas, l'acte de transmettre affecte l'acteur responsable de la transmission. La réception peut, quant à elle, être active ou passive, les deux situations impliquant la recherche volontaire ou l'imposition de l'objet en question. La réception, elle-même conditionnée par plusieurs considérations, peut entraîner le refus, mais aussi l'appropriation, c'est-à-dire l'acceptation et l'intégration d'un objet transmis qui subit souvent une forme de transformation. L'entité réceptrice est cependant toujours affectée, à un degré plus ou moins important, par la réception et surtout par l'appropriation. En théorie, nous avons tenté de définir, de façon toujours plus ou moins arbitraire, des »unités de transfert« avec un >début et une >fin`. À partir d'une telle notion, il a été possible de définir différents degrés de complexité, de la simple séquence à l'imbrication de plusieurs séquences dans les différentes sphères géographiques, temporelles et/ou sociales. 
Ainsi envisagée, la notion de transfert culturel peut se révéler d'une utilité certaine pour décrire, comprendre et classer les différentes formes de contacts et d'échanges culturels. Le contexte de la Méditerranée médiévale, caractérisé par la formation des grands ensembles culturels et marqué par la complexité des interférences et des superpositions, est un terrain idéal pour une telle expérimentation. Notre approche, se voulant claire et flexible, ambitionne de contribuer à une meilleure perception des phénomènes étudiés, sans prétendre exclure d'autres lectures faites selon des notions différentes ni remettre en cause leur potentiel herméneutique. 